\title{
Kinematic energy balance approach to submarine landslide evolution
}

\section{Journal Article}

\section{Author(s):}

Buss, Christian; Friedli, Balz; Puzrin, Alexander M.

Publication date:

2019-09

Permanent link:

https://doi.org/10.3929/ethz-b-000365016

Rights / license:

Creative Commons Attribution 4.0 International

Originally published in:

Canadian Geotechnical Journal 56(9), https://doi.org/10.1139/cgj-2017-0651

\section{Funding acknowledgement:}

168998 - Dynamic evolution of submarine landslides (SNF) 


\title{
Kinematic energy balance approach to submarine landslide evolution $^{1}$
}

\author{
Christian Buss, Balz Friedli, and Alexander M. Puzrin
}

\begin{abstract}
The paper applies the energy balance kinematic method of plasticity theory to the large deformation problem of initiation and propagation of the spreading and ploughing failure outside a failed slab in submarine sediments. The models account for the phenomenon of the progressive propagation of a slope parallel slip surface, which is also quantified using the energy balance approach. In contrast to existing approximate analytical and numerical solutions, the proposed approach provides a theoretical basis for spreading and ploughing criteria as well as the comprehensive dynamic solution of the problem of post-failure landslide evolution. Incremental integration of the derived analytical expressions for kinetic energy in time allows for modelling recurrent initiation of new kinematic failure mechanisms with their subsequent large-scale deformation. Treating the failed slab as well as the spreading and ploughing mechanisms as one composite dynamically evolving mass movement allows for the final post-failure geomorphology of the failed slope to be predicted using basic mechanical principles.

Key words: submarine landslides, energy balance, kinematic approach, progressive failure, spreading, ploughing.

Résumé : L’article applique la méthode cinématique du bilan énergétique de la théorie de la plasticité au grand problème de déformation de l'initiation et de la propagation de la rupture d'épandage et de labourage à l'extérieur d'une dalle défectueuse dans les sédiments sous-marins. Les modèles rendent compte du phénomène de propagation progressive d'une surface de glissement parallèle à une pente, qui est également quantifié à l'aide de l'approche du bilan énergétique. Contrairement aux solutions analytiques et numériques approximatives existantes, l'approche proposée fournit une base théorique pour les critères d'épandage-labourage et la solution dynamique globale du problème de l'évolution des glissements de terrain après l'échec. L'intégration incrémentale des expressions analytiques dérivées pour l'énergie cinétique dans le temps permet de modéliser l'initiation récurrente de nouveaux mécanismes de rupture cinématique avec leur déformation ultérieure à grande échelle. Le traitement de la dalle échouée ainsi que des mécanismes d'épandage et de labourage sous la forme d'un mouvement de masse composite évoluant dynamiquement permet de prédire la géomorphologie finale après défaillance de la pente défaillante en utilisant des principes mécaniques de base. [Traduit par la Rédaction]
\end{abstract}

Mots-clés : glissements sous-marins, bilan énergétique, approche cinématique, échec progressif, épandage, labourage.

\section{Introduction}

Gigantic dimensions and peculiar geomorphology of historic submarine landslides have generated significant scientific interest in the literature (e.g., Hampton et al. 1996; Locat and Lee 2002; Bryn et al. 2005; Masson et al. 2006), in particular due to their potential tsunami hazard (see recent reviews by Grilli et al. 2017; Lovholt et al. 2017). Offshore and coastal developments have further highlighted the need for reliable hazard assessment, requiring understanding of the mechanisms of dynamic landslide evolution - from pre-failure conditioning, triggering, nucleation, and propagation of localized shear zones to global failure and post-failure processes.

The shear band propagation (SBP) approach for submarine slope stability analysis helps to explain how a relatively short initial slip surface (localized shear zone of finite thickness, marked in red in Fig. 1) can, under specific conditions, propagate dynamically tens of kilometres parallel to the slope surface through the quasistable part of the slope (orange in Fig. 1), eventually causing a slab failure. This approach, proposed by Puzrin et al. (2004) and Puzrin and Germanovich (2005) based on fracture mechanics prin- ciples developed by Palmer and Rice (1973), allows determination of the landslide geometry (for a slab failure), volume, and breakoff velocity, providing more reliable input parameters for debris flow and tsunami wave propagation analysis (Puzrin et al. 2010; Trapper et al. 2015). In the past few years, a number of novel analytical, numerical, and experimental tools have been developed and validated (Viesca and Rice 2012; Puzrin et al. 2015, 2016; Germanovich et al. 2016; Zhang et al. 2016, 2017), extending the SBP approach to account for actual nonlinear slope geometries, different types of triggers (excess pore-water pressures, seismic loading). and dynamic propagation effects. Moreover, an attempt has been made to relate the observed spreading and ploughing mechanisms (formed above and below the failed slab, respectively, see Fig. 1) to progressive propagation of a slope parallel slip surface into the stable part of the slope using simplified analytical criteria (Puzrin 2016; Puzrin et al. 2017).

In parallel, a significant body of work has been devoted to studying spreading and ploughing problems numerically. Progressive spreading failure accompanied by an uphill growth of the shear band in subaerial landslides driven by the removal of the downslope support has been studied using finite element (FE) analysis

Received 9 November 2017. Accepted 29 May 2018.

C. Buss, B. Friedli, and A.M. Puzrin. Institute for Geotechnical Engineering, ETH Zurich, 8093 Zurich, Switzerland.

Corresponding author: Alexander M. Puzrin (email: alexander.puzrin@igt.baug.ethz.ch).

'This paper is part of a Special Issue entitled “Advances in landslide understanding”.

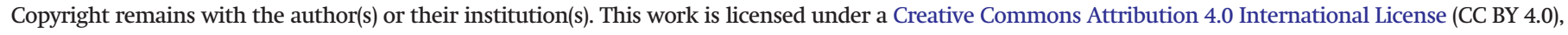
which permits unrestricted use, distribution, and reproduction in any medium, provided the original author(s) and source are credited. 
Fig. 1. Submarine landslide evolution.

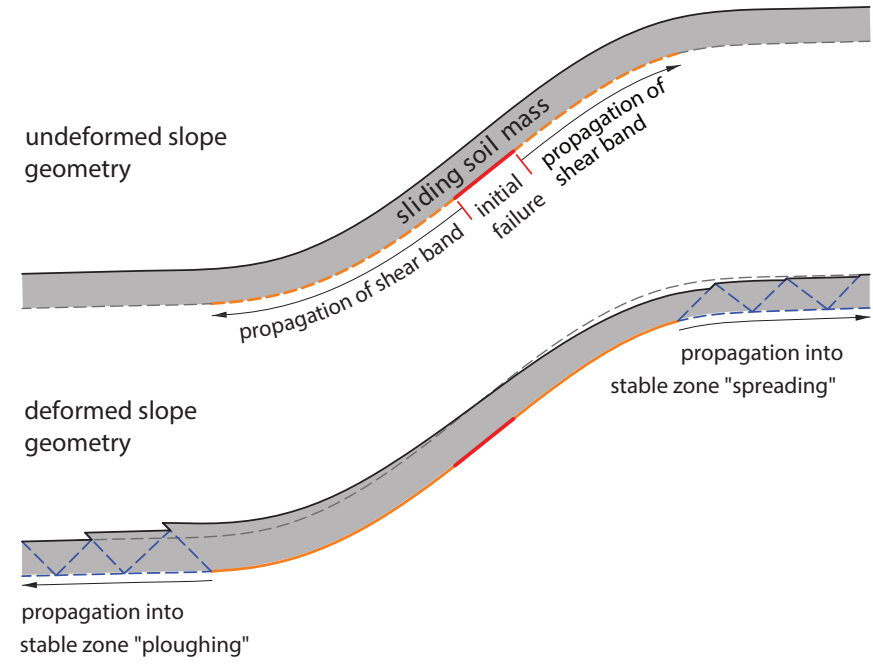

(e.g., Locat et al. 2011, 2013; Quinn et al. 2011, 2012; Dey et al. 2015). In more recent publications (e.g., Trapper et al. 2015; Dey et al. 2016; Zhang et al. 2019), large-deformation FE analysis was applied to explore the SBP-driven post-failure evolution of submarine landslides. While sophisticated FE analysis can provide insight into the basic landslide mechanisms, its large computational costs limit hazard assessment to deterministic analysis of small seafloor areas (e.g., Locat and Lee 2002; Vanneste et al. 2013).

Probabilistic slope stability analysis of large marine basins requires therefore an analytical framework not only providing criteria for spreading-ploughing initiation, but also predicting the post-failure deformations. In this respect, particularly promising is the energy balance approach proposed by Kvalstad et al. (2005) and used by Lovholt et al. (2016) for modelling the kinematics of submarine spreading failures. Studying gravity tectonics on passive margins, Peel (2014) suggested that the energy approach should be applied to the entire mass movement, including the failed slab, spreading, and ploughing regions. The present work combines the energy balance kinematic approach of plasticity theory with the energy balance approach to the SBP, providing a more rigorous analytical framework describing the large-deformation landslide phenomena as a synthesis of various interconnected postfailure processes.

\section{Problem formulation}

The phenomena explored in this paper take place after a slab failure of a portion of submarine slope. The movement of the slab is preceded by the formation and propagation of a slope parallel slip surface (SPSS) at its base. Due to this SPSS propagation, the intact slab experiences loading in its downslope and unloading in the upslope portions, which can eventually reach compression and extension failure, respectively, within the slab body. Once failed, the slab often runs out at the bottom and leaves a scarp at the top of the slope. Under certain conditions, however, the slope continues to fail both up- and downhill from the intact slab (Fig. 2), with the kinematic failure mechanisms recurring within the sliding body. This paper explores these conditions and the subsequent failure evolution using rigorous energy-based kinematic methods. The solution of this problem is achieved through the following three steps:

1. Formulate conditions for the initial slab failure.

2. Describe the evolution of the first failure mechanism in the sliding body, accompanied by large deformation and softening.

3. Formulate conditions for the recurrence of the failure mechanisms up- and downslope (spreading and ploughing, respectively).
The analysis of these three stages is performed with the help of a free-body cut separating the intact slab from the rest of the slope (Fig. 2). This allows for the failure evolution at the two slab edges to be investigated independently. Interaction of the intact slab with the failed edges takes place through the slope parallel forces $Q_{u}$ and $Q_{1}$, at the top and at the bottom, respectively. The criteria will be developed to determine when these forces cause initial failure and at what level they can cause subsequent retrogressive spreading at the top and progressive ploughing at the bottom of the slope. While the original intact slab is curved, the regions where failure mechanisms develop are assumed (for simplicity) to have a constant slope inclination.

After the up- and downslope failures are described separately, it will be demonstrated how the approach can be applied to the whole curved slope as one mechanism, allowing for definition of the final geomorphology of landslide deposits.

\section{Assumptions}

The solution of the above problem requires certain assumptions with respect to the material behaviour. Due to the low permeability of submerged marine sediments and the fast loading rates, purely undrained failure conditions are assumed. The contractive behaviour of loose marine sediments often leads to strainsoftening after reaching a peak shear resistance. In this study, the complex undrained soil behaviour of the sliding body is idealized by assuming linear elastic - plastic behaviour with the Tresca failure criterion, where the undrained shear strength $s_{\mathrm{u}}$ softens with increasing plastic shear strain, $\gamma^{\mathrm{P}}$, from its peak value, $s_{\mathrm{up}}$, to residual value, $s_{\mathrm{ur}}$ (Fig. $3 a$ ). In the case of strain localization within the sliding layer (formation of a shear band), the displacement jump, $\delta$, along such a shear band is related to the plastic strain and the width of the shear band, $d_{\mathrm{SB}}$, by the expression

$$
\frac{\delta}{d_{\mathrm{SB}}}=\tan \gamma^{\mathrm{p}}=\chi
$$

Although in reality the undrained shear strength varies in depth as a function of the initial effective stress and degree of overconsolidation, here, as a first approximation, a uniform strength distribution (averaged over the thickness of the sliding layer) is assumed. It is also assumed that the sliding layer is bounded at the bottom (at the constant depth $h$ ) by a weaker layer with different properties. Recent site investigations have indicated that submarine landslides are typically initiated at a weakened layer, within which the ratio of undrained shear strength to the effective normal stress is lower than for adjacent layers (Kvalstad et al. 2005; Gee et al. 2005; Sultan et al. 2010; L'Heureux et al. 2012; Gray et al. 2015). The elastic response of the sliding layer in the slope parallel direction is important for the SBP along the SPSS. Following Palmer and Rice (1973) and Puzrin and Germanovich (2005), this elastic deformation is taken into account for the assessment of the propagation length of the shear band. In contrast, the threshold force at which the slab starts to develop plastic deformation (that is, forms a mechanism) at its edges and the subsequent evolution of the plastic deformation are formulated with the assumption of rigid-plastic strain-softening material behaviour. This assumption is justified by the fact that in the failed region of the slope outside of the slab, the neglected elastic strain energy rate is small compared to the rate of plastic dissipation and the change in the potential energy.

Following Puzrin and Germanovich (2005), the soil within the SPSS is assumed to be rigid-plastic with the peak strength value, $\tau_{\mathrm{p}}$, and exhibits strain-softening behaviour until the residual strength value, $\tau_{\mathrm{r}}$, is reached at the displacement $\delta_{\mathrm{r}}$ (Fig. $3 b$ ). The deformations below the SPSS are neglected.

Although loose marine sediments usually show an increase of density with effective stress (close to the ground surface), for the 
Fig. 2. Free-body cut of failure regions showing slope parallel forces at the top $\left(Q_{\mathrm{u}}\right)$ and bottom $\left(Q_{1}\right)$ of the slab slide.

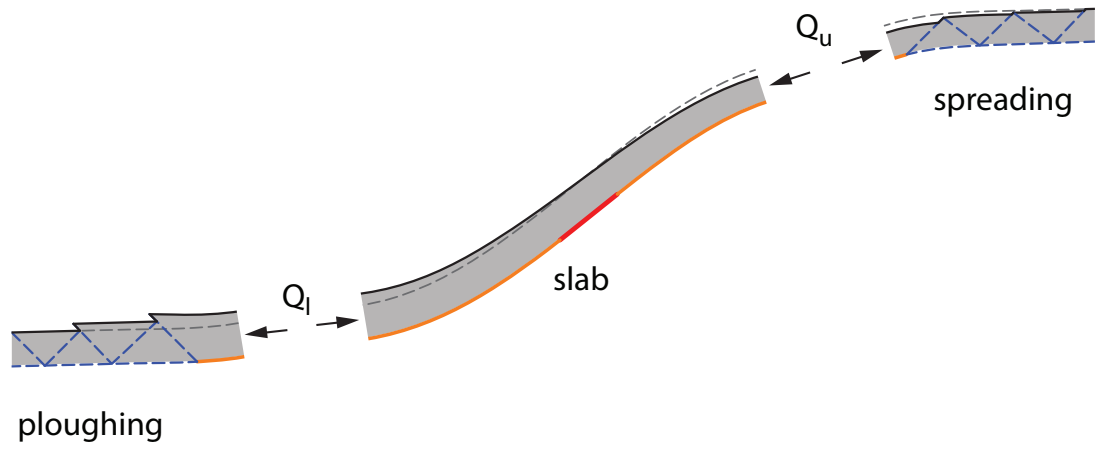

Fig. 3. Material strengths in (a) sliding slab; (b) slope parallel slip surface (SPSS). $\bar{\delta}$, characteristic displacement.

(a)

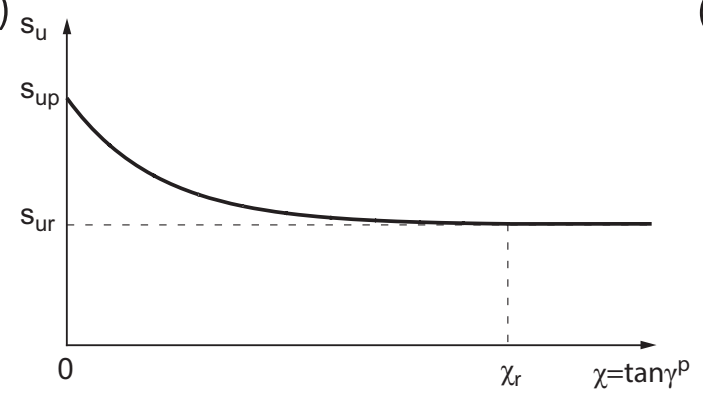

(b)

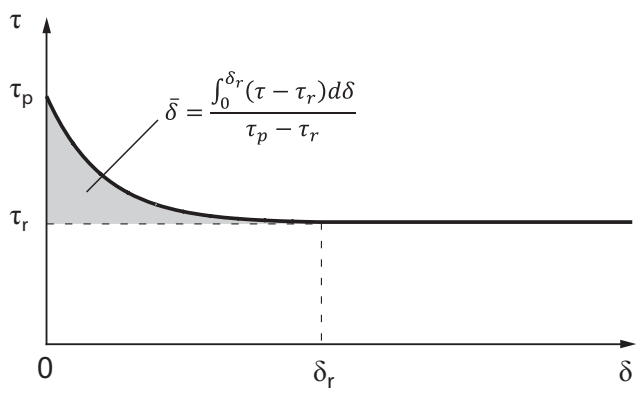

sake of simplicity the total unit weight of soil, $\gamma$, is assumed constant in this paper. For submerged landslides only, the effective unit weight of the soil, $\gamma^{\prime}=\gamma-\gamma_{w}$ (where $\gamma_{w}$ is the unit weight of water) contributes to driving forces. In contrast, inertia forces depend on the total soil density, $\rho=\gamma / g$ (where $g$ is the acceleration due to gravity).

\section{Kinematic energy balance (KEB) approach for large deformations}

After the initially intact slab body fails in extension at the top and compression at the bottom of the slope, it keeps unloadingloading the adjacent slope regions by the drop-heave in the seabed surface due to large deformations of the respective failure wedges. During this process the geometry of the failure zones changes dramatically and therefore the effects of not only material but also geometric softening and hardening have to be taken into account.

Accounting for the complete phenomena of elastic-plastic loading or unloading with geometric as well as material hardening and softening proves to be a complicated task, that in general can only be solved numerically using, for example, the FE method. To develop a simplified analytical approach to the analysis of postfailure evolution in submarine landslides, an extended kinematic method of limit analysis can be applied to describe plastic deformations (e.g., Kvalstad et al. 2005). The method has certain similarities to the upper bound-based strain path method proposed by Einav and Randolph (2005) and to the method applied by Alonso and Pinyol (2010) for the evolution of the Vaiont landslide. Similar to the classical kinematic method (e.g., Drucker and Prager 1952; Chen 1975), a kinematically admissible velocity field (i.e., a collapse mechanism) is assumed, based on which the work equation is formulated. In contrast to the classical kinematic method, however, where the work equation is formulated based on a virtual velocity field, here finite velocities and displacements are considered. Consequently, to fulfil the kinematic conditions (i.e., mass conservation) and boundary conditions, material has to be sheared across velocity discontinuities leading to a change in geometry. Similar to the classical kinematic method, the most critical collapse mechanism can be found by optimization of the geometry. Strictly speaking this should be done for every deformation state of the failure evolution. In the present study, however, it is assumed that the optimized location of the velocity discontinuities for the initial collapse mechanism (i.e., corresponding to zero displacements) is also valid for the subsequent large failure deformation. Indeed, once the initial strain localization takes place, due to the material softening it is highly likely that shear deformations will continue to be confined to the existing velocity discontinuity. The current state of the system is obtained by integrating the energy rates over time starting from the initial state. This approach allows not only taking into account the geometric nonlinearity, but also material softening, as finite strains and displacements can be calculated by integrating velocities. Furthermore, if the system is unstable, this approach allows for the description of the dynamic post-failure evolution by calculating the total kinetic energy of the system at every state of the loading history. In the following sections, this method, which in this paper is denoted as kinematic energy balance (KEB) approach, is applied for assessing the post-failure evolution of submarine landslides, first at the top (unloading) and then at the bottom (loading) of the sliding slab.

\section{Initial failure due to unloading at top of sliding slab}

In this section, the KEB approach is applied with the goal of formulating the condition for initial failure at the top of the sliding slab (onset of the development of plastic deformation in the slab body) and the subsequent evolution of the force in the upper part of the slope as a function of the state of plastic deformation. To achieve these goals, first, a kinematically admissible mechanism is introduced and the rate of kinetic energy is calculated as a function of the state of deformation. Then, following the concepts of limit analysis, the geometry of the mechanism for the initial failure state is optimized using the principle of minimal energy. Finally, the condition for the failure initiation is formulated in terms of the limiting slope parallel force. 
Fig. 4. Kinematics of large-deformation unloading mechanism. $u_{\mathrm{d}}$, drop in height; $V_{\mathrm{su}}$, volume of the sheared material; $X$, length; $\alpha$, slope inclination.

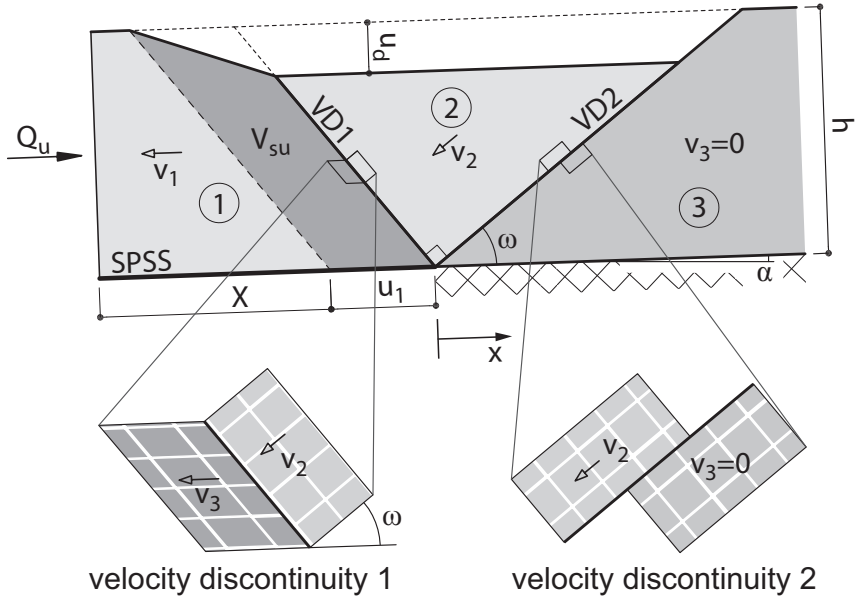

\section{Initial unloading failure mechanism}

The proposed kinematic mechanism (Fig. 4) has one free geometric parameter, $\omega$. It consists of three blocks and two velocity discontinuities, VD1 and VD2 inclined, respectively, by the angles $\omega$ and $\omega+\pi / 2$ with respect to the slip surface. Block 1 represents a part of the sliding slab of thickness $h$, which moves downslope with velocity $v_{1}$. The remaining part of the slab is replaced at a free cut $x$ by its slope parallel reaction $Q_{u}$, which will contribute to the work of external forces together with the gravity forces. Block 2 is an active wedge moving with the velocity $v_{2}$ parallel to the velocity discontinuity VD2, while block 3 remains stable (conditions for the propagation of failure below and across block 3 are derived later in this paper).

The displacements of the deformed system are found by integrating the velocities of the respective blocks with respect to time, $t$

$$
u_{i}=\int v_{i} d t
$$

The velocities and displacements of blocks 1 and 2 are, therefore, both related by

$$
\begin{aligned}
& v_{2}=\cos \omega v_{1} \\
& u_{2}=\cos \omega u_{1}
\end{aligned}
$$

The corresponding drop in height of block 2 is

$$
u_{\mathrm{d}}=\sin \omega u_{2}=\cos \omega \sin \omega u_{1}
$$

To fulfil kinematic admissibility (i.e., volume conservation), this drop in height results in soil crossing velocity discontinuity VD1, where its velocity changes from $v_{2}$ to $v_{1}$ and the soil is subjected to the plastic shear deformation $\gamma_{\mathrm{VD} 1}^{\mathrm{p}}=\tan ^{-1} \chi_{\mathrm{VD} 1}=\omega$ equal to the angle between the two velocities. At every displacement increment a new portion of the sheared material crosses VD1 and contributes to the evolving smeared shear zone. In contrast, no material crosses the velocity discontinuity VD2, where additional shearing takes place along a thin shear band. The plastic shear strain in VD2 can be determined using equation (1)

$$
\gamma_{\mathrm{VD} 2}^{\mathrm{p}}=\tan ^{-1} \chi_{\mathrm{VD} 2} \quad \text { where }\left\{\begin{array}{l}
\chi_{\mathrm{VD} 2}=\frac{\delta_{\mathrm{VD} 2}}{d_{\mathrm{SB}, \mathrm{VD} 2}} \\
\delta_{\mathrm{VD} 2}=u_{2}=\cos \omega u_{1}
\end{array}\right.
$$

\section{Work equation}

The mechanism in Fig. 4 will, in general, accelerate due to softening of the material, with kinetic energy rate, $\dot{E}_{\text {kin }}$, calculated as the difference between the rates of external work, $\dot{W}_{\mathrm{e}}$, and dissipation, $\dot{D}_{\mathrm{i}}$,

$$
\begin{aligned}
\dot{\mathrm{E}}_{\mathrm{kin}}=\dot{\mathrm{W}}_{\mathrm{e}}-\dot{D}_{\mathrm{i}}=\dot{W}_{\mathrm{e}}\left(Q_{\mathrm{u}}, v_{1}\right)+ & \dot{W}_{\mathrm{e}}\left(G_{1}^{\prime}, v_{1}\right)+\dot{W}_{\mathrm{e}}\left(G_{2}^{\prime}, v_{2}\right) \\
& -\left(\dot{D}_{\mathrm{iSPSS}}+\dot{D}_{\mathrm{iVD} 1}+\dot{D}_{\mathrm{iVD} 2}\right)
\end{aligned}
$$

where $G^{\prime}$ is the effective weight of the corresponding blocks.

The weights of blocks 1 and 2 have to be evaluated to calculate the change in their potential energy (work increments of gravity forces). The initial volumes of blocks 1 and 2 are

$$
V_{10}=h\left(X-\frac{h \tan \omega}{2}\right) \quad V_{20}=\frac{h^{2}}{2 \cos \omega \sin \omega}
$$

where $X$ is the measure defined in Fig. 4 .

The volume of the sheared material that has crossed the velocity discontinuity VD1 from block 2 to block 1 is

$$
V_{\mathrm{su}}=\int\left(h-u_{\mathrm{d}}\right) v_{1} d t=\int\left(h-u_{\mathrm{d}}\right) d u_{1}=\left(h-\frac{u_{\mathrm{d}}}{2}\right) u_{1}
$$

and is equal to the area of the grey smeared shear zone in Fig. 4.

For submerged slopes only, the effective soil weight has to be taken into account when calculating the external work of the gravity. The rate of external work of the gravity acting on blocks 1 and 2 and the reaction force $Q_{\mathrm{u}}$ acting on block 1 is

$$
\begin{aligned}
\dot{W}_{\mathrm{e}}\left(Q_{\mathrm{u}}, v_{1}\right) & +\dot{W}_{\mathrm{e}}\left(G_{1}^{\prime}, v_{1}\right)+\dot{W}_{\mathrm{e}}\left(G_{2}^{\prime}, v_{2}\right)=-Q_{\mathrm{u}} v_{1} \\
& +\left(V_{10}+V_{\mathrm{su}}\right) \gamma^{\prime} v_{1} \sin \alpha+\left(V_{20}-V_{\mathrm{su}}\right) \gamma^{\prime} v_{2} \sin (\omega+\alpha)
\end{aligned}
$$

where $\alpha$ is the slope inclination as defined in Fig. 4.

The dissipation rate along the slip surface is calculated from the velocity of block 1 and the resistance, $\tau$, on the slip surface.

$$
\dot{D}_{\mathrm{iSPSS}}=\int_{-X-u_{1}}^{0} \tau(x) v_{1} d x
$$

The dissipation rate along the velocity discontinuity between blocks 2 and 3 (VD2 in Fig. 4) is calculated by integrating the product of the relative velocity, $v_{2}$, and the corresponding shear resistance, $s_{\mathrm{u}}\left(\gamma_{\mathrm{VD} 2}^{\mathrm{P}}\right)$, along the length of VD2, which changes depending on the drop in height of block 2 .

$$
\dot{D}_{\mathrm{iVD} 2}=s_{\mathrm{u}}\left(\chi_{\mathrm{VD} 2}\right) \frac{\left(h-u_{\mathrm{d}}\right)}{\sin \omega} v_{2}
$$

The dissipation rate in the shear zone between blocks 1 and 2 (VD1 in Fig. 4) is obtained using eq. (8)

$$
\dot{D}_{\mathrm{iVD} 1}=\dot{V}_{\mathrm{su}} \int_{0}^{\gamma^{\mathrm{p}}=\omega} s_{\mathrm{u}}\left(\gamma^{\mathrm{p}}\right) d \gamma^{\mathrm{p}}=\left(h-u_{\mathrm{d}}\right) v_{1} \int_{0}^{\chi_{\mathrm{VD} 1}=\tan \omega} s_{\mathrm{u}}(\chi) d \chi
$$

By substituting eqs. (9)-(12) into eq. (6), the following expression for the kinetic energy rate is obtained: 


$$
\begin{aligned}
& \dot{E}_{\text {kin }}=-Q_{\mathrm{u}} v_{1}+\left(V_{10}+V_{\mathrm{su}}\right) \gamma^{\prime} v_{1} \sin \alpha \\
& +\left(V_{20}-V_{\mathrm{su}}\right) \gamma^{\prime} v_{2} \sin (\omega+\alpha)-\left(h-u_{\mathrm{d}}\right) v_{1} \int_{0}^{\tan \omega} s_{\mathrm{u}}(\chi) d \chi \\
& \quad-s_{\mathrm{u}}\left(\chi_{\mathrm{VD} 2}\right) \frac{\left(h-u_{\mathrm{d}}\right)}{\sin \omega} v_{2}-\int_{-X-u_{1}}^{0} \tau(x) v_{1} d x
\end{aligned}
$$

\section{Optimizing the mechanism geometry}

Having formulated the terms of the work equation, the free parameter of the mechanism, the angle $\omega$, has to be optimized. The most probable geometry of the mechanism is found by following the minimum energy principle. This optimization is done for the initial failure by formulating the kinetic energy rate for zero displacement $u_{1}=0$. In this case, from eqs. (4), (5), (8), and (13), it follows that $u_{\mathrm{d}}=0, V_{\mathrm{su}}=0$, and $\mathrm{X}_{\mathrm{VD} 2}=0$, resulting in

$$
\begin{aligned}
\dot{E}_{\mathrm{kin}}=\left\{\gamma^{\prime} h X \sin \alpha+\frac{\gamma^{\prime} h^{2}}{2}[\sin \alpha(\cot \omega-\tan \omega)+\cos \alpha]\right. \\
\left.\quad-h \int_{0}^{\tan \omega} s_{\mathrm{u}}(\chi) d \chi-h s_{\mathrm{up}} \cot \omega-\int_{-X}^{0} \tau(x) d x-Q_{\mathrm{u}}\right\} v_{1}
\end{aligned}
$$

where $s_{\mathrm{up}}=s_{\mathrm{u}}\left(\chi_{\mathrm{VD} 2}=0\right)$.

Following the minimum energy principle, the optimum angle, $\omega_{\text {opt }}$, is found from the equation $\partial \dot{E}_{\text {kin }} / \partial \omega=0$

$$
\tan \omega_{\mathrm{opt}}=\chi_{\mathrm{opt}}=\sqrt{\frac{2 s_{\mathrm{up}}-h \gamma^{\prime} \sin \alpha}{2 s_{\mathrm{u}}\left(\chi=\tan \omega_{\mathrm{opt}}\right)+h \gamma^{\prime} \sin \alpha}}
$$

For perfectly plastic soil behaviour, $s_{\mathrm{u}}(X)=s_{\mathrm{up}}=$ constant and horizontal ground surface $\alpha=0$, the above equation gives $X_{\mathrm{opt}}=1$ (i.e., the optimum angle $\omega_{\text {opt }}=\pi / 4$ ), as in the classical undrained active failure mechanism. In the case of strain-softening and mild slope inclinations $\alpha$, eq. (15) gives $X_{\mathrm{opt}} \cong 1$, i.e., the shear strain along the velocity discontinuity between blocks 1 and 2 (VD1 in Fig. 4) is approximately $100 \%$. Such strains would most likely cause the full softening of the material: $s_{\mathrm{u}}(X \cong 1) \cong s_{\mathrm{ur}}$, so that the optimal geometry of the mechanism can well be approximated as

$$
\tan \omega_{\mathrm{opt}}=\chi_{\mathrm{opt}} \cong \sqrt{\frac{2 s_{\mathrm{up}}-h \gamma^{\prime} \sin \alpha}{2 s_{\mathrm{ur}}+h \gamma^{\prime} \sin \alpha}}
$$

Once the geometry of the initial failure mechanism has been defined, criteria for initial failure at the top of the sliding slab are formulated.

\section{Conditions for initial failure}

Following the principles of limit analysis, the condition for initial (static) failure is determined by the energy balance equation

$$
\dot{\mathrm{E}}_{\mathrm{kin}}\left(u_{1}=0, \omega=\omega_{\text {opt }}\right)=\dot{W}_{\mathrm{e}}-\dot{D}_{\mathrm{i}}=0
$$

The initial failure will take place at the intersection of velocity discontinuities VD1 and VD2 in Fig. 4, where the slope parallel force $Q_{\mathrm{u}}$ in the sliding slab reaches its minimum and where the origin of coordinate $x$ is set. For optimized geometry and $x=0$, applying the condition defined by eq. (17) to eq. (14) gives the limiting slope parallel force in the sliding slab, $Q_{\mathrm{u}}^{\mathrm{f}}$, that would lead
Fig. 5. Dynamic equilibrium in slope parallel direction. G, weight of blocks; $I$, inertia force $Q_{a}$, force acting between mechanism and stable slope.

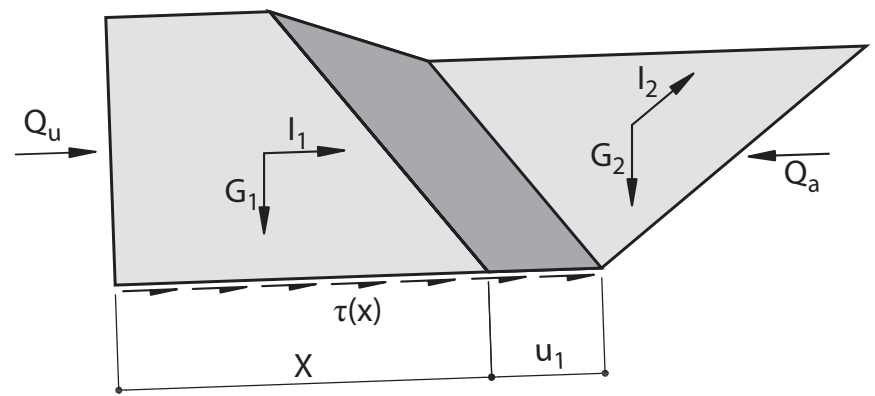

to formation of the initial failure mechanism in the slab due to unloading

$$
Q_{\mathrm{u}}^{\mathrm{f}}=\frac{\gamma^{\prime} h^{2}}{2}\left[\sin \alpha\left(\frac{1-\chi_{\mathrm{opt}}^{2}}{\chi_{\mathrm{opt}}}\right)+\cos \alpha\right]-h\left[\int_{0}^{\chi_{\mathrm{opt}}} s_{\mathrm{u}}(\chi) d \chi+\frac{s_{\mathrm{up}}}{\chi_{\mathrm{opt}}}\right]
$$

For perfectly plastic soil behaviour, $s_{\mathrm{u}}(X)=s_{\mathrm{up}}=$ constant and horizontal ground surface $\alpha=0$, eq. (15) gives $X_{\mathrm{opt}}=1$, so that the limiting force (eq. (18)) reduces to $Q_{\mathrm{u}}^{\mathrm{f}}=\frac{\gamma^{\prime} h^{2}}{2}-2 s_{\mathrm{up}} h$ as in the classical undrained active failure mechanism.

Once the force $Q_{\mathrm{u}}^{\mathrm{f}}$ is reached in the uphill part of the slab, the initial failure mechanism (Fig. 4) will form. Continuing downhill displacement of the slab will cause evolution of this mechanism, which will result in the further unloading of the stable part of the slope.

\section{Evolution of initial failure mechanism at top of sliding slab}

Once the force $Q_{u}^{\mathrm{f}}$ is reached in the uphill part of the slab, the initial failure mechanism (Fig. 4) will form. Continuing downhill displacement of the slab will cause further evolution of this mechanism. The direction and location of the velocity discontinuities VD1 and VD2 are not likely to deviate from the angle $\omega_{\text {opt }}$ of the initial failure mechanism due to material softening and the resulting shear strain localization. Displacements of the mechanism will result in the further unloading of the stable part of the slope and, potentially, propagation of the failure into this stable part. In the following section this unloading is quantified by calculating the slope parallel force $Q_{\mathrm{a}}$, which is acting between blocks 2 and 3 during the evolution of the initial unloading mechanism (Fig. 5). The rate of kinetic energy for the evolving mechanism has been calculated from the energy balance equation (eq. (13)) as the difference between the external work and internal dissipation rates. It can be also calculated by differentiating the total kinetic energy of blocks 1 and 2 with respect to time

$$
\begin{gathered}
\dot{E}_{\mathrm{kin}}=\frac{\partial\left[\frac{1}{2} \rho\left(V_{10}+V_{\mathrm{su}}\right) v_{1}^{2}+\frac{1}{2} \rho\left(V_{20}-V_{\mathrm{su}}\right) v_{2}^{2}\right]}{\partial t} \\
=\rho\left[\left(V_{10}+V_{20} \frac{1}{\chi_{\mathrm{opt}}^{2}+1}+V_{\mathrm{su}} \frac{\chi_{\mathrm{opt}}^{2}}{\chi_{\mathrm{opt}}^{2}+1}\right) \dot{v}_{1}+\frac{1}{2} \dot{V}_{\mathrm{su}} \frac{\chi_{\mathrm{opt}}^{2}}{\chi_{\mathrm{opt}}^{2}+1} v_{1}\right] v_{1}
\end{gathered}
$$

where the soil density, $\rho$, is introduced. Substituting eq. (19) into the energy balance equation (eq. (13)) provides the expression relating the slab force, $Q_{\mathrm{u}}$, to the acceleration, $\dot{v}_{1}$, and velocity, $v_{1}$, of the mechanism 


$$
\begin{array}{r}
Q_{\mathrm{u}}=\gamma^{\prime}\left[\left(V_{10}+V_{20}\right) \sin \alpha+\left(V_{20}-V_{\mathrm{su}}\right) \frac{\chi_{\mathrm{opt}}\left(\cos \alpha-\chi_{\mathrm{opt}} \sin \alpha\right)}{\chi_{\mathrm{opt}}^{2}+1}\right]-\left(h-u_{\mathrm{d}}\right)\left[\int_{0}^{\chi_{\mathrm{opt}}} s_{\mathrm{u}}(\chi) d \chi+\frac{s_{\mathrm{u}}\left(\chi_{\mathrm{VD} 2}\right)}{\chi_{\mathrm{opt}}}\right] \\
-\int_{-X-u_{1}}^{0} \tau(x) d x-\rho\left(V_{10}+V_{20} \frac{1}{\chi_{\mathrm{opt}}^{2}+1}+V_{\mathrm{su}} \frac{\chi_{\mathrm{opt}}^{2}}{\chi_{\mathrm{opt}}^{2}+1}\right) \dot{v}_{1}-\frac{1}{2} \rho \dot{V}_{\mathrm{su}} \frac{\chi_{\mathrm{opt}}^{2}}{\chi_{\mathrm{opt}}^{2}+1} v_{1}
\end{array}
$$

Formulating the equation of motion in the slope parallel direction includes inertia forces $I_{1}$ and $I_{2}$, which can be found from time derivatives of the momentum of blocks 1 and 2, respectively

$$
\begin{aligned}
& I_{1}=\frac{\partial\left[\rho\left(V_{10}+V_{\text {su }}\right) v_{1}\right]}{\partial t}= \rho\left(V_{10}+V_{\text {su }}\right) \dot{v}_{1}+\rho \dot{V}_{\text {su }} v_{1} \\
& I_{2}=\frac{\partial\left[\rho\left(V_{20}-V_{\mathrm{su}}\right) v_{2}\right]}{\partial t}=\rho\left(V_{20}-V_{\text {su }}\right) \frac{1}{\sqrt{\chi_{\text {opt }}^{2}+1}} \dot{v}_{1} \\
&-\rho \dot{V}_{\text {su }} \frac{1}{\sqrt{\chi_{\text {opt }}^{2}+1}} v_{1}
\end{aligned}
$$

The equation of motion in the slope parallel direction is given by

$$
\begin{aligned}
Q_{\mathrm{a}}=Q_{\mathrm{u}}+\int_{-X-u_{1}}^{0} \tau(x) d x+I_{1}+I_{2} \frac{1}{\sqrt{\chi_{\mathrm{opt}}^{2}+1}} & -\gamma^{\prime}\left(V_{10}+V_{20}\right) \sin \alpha
\end{aligned}
$$

which after substitution of the slab force $Q_{u}$ from eq. (20) and inertia forces from eq. (21) provides the expression for the force $Q_{a}$ acting on the stable part of the slope as a function of the drop of the seabed surface, $u_{\mathrm{d}}$, velocity of the mechanism, $v_{1}$, slope geometry, $\alpha$, and shear strength of the soil, $s_{\mathrm{u}}$

$$
Q_{\mathrm{a}}\left(u_{\mathrm{d}}, v_{1}\right)=\frac{a}{2}\left(h-u_{\mathrm{d}}\right)^{2}-b\left(h-u_{\mathrm{d}}\right)
$$

where

$$
\begin{aligned}
& a=\gamma^{\prime}\left(\cos \alpha-\chi_{\mathrm{opt}} \sin \alpha\right) \\
& b=\frac{s_{\mathrm{u}}\left(\chi_{\mathrm{VD} 2}\right)}{\chi_{\mathrm{opt}}}+\int_{0}^{\chi_{\mathrm{opt}}} s_{\mathrm{u}}(\chi) d \chi-\frac{1}{2} \rho \frac{\chi_{\mathrm{opt}}^{2}}{\chi_{\mathrm{opt}}^{2}+1} v_{1}^{2}
\end{aligned}
$$

This unloading force, $Q_{\mathrm{a}}\left(u_{\mathrm{d}}, v_{1}\right)$, does not depend on the slab force $Q_{u}$, justifying the application of the free-body cut of the slab in the above analysis. Knowing the evolution of this force is essential for formulating conditions at which the initially stable upper part of the slope (block 3 ) becomes unstable, potentially leading to retrogressive failure.

\section{Spreading failure criterion}

\section{Retrogressive failure mechanism}

As the sliding slab continues to move downslope, the evolution of the initial failure mechanism shown in Fig. 5 results in a drop in the seabed surface and in a decrease of the force $Q_{\mathrm{a}}\left(u_{\mathrm{d}}, v_{1}\right)$, which supports the upper, stable part of the slope. This gradual unloading leads to decreasing compressive stresses in the stable part and progressive propagation (Puzrin et al. 2017) of the SPSS uphill, eventually causing the formation of the next failure mechanism, upslope from the initial one (Fig. 6). This recurrent formation of failure mechanisms explains the process behind the retrogressive failures observed in spreads. The same large deformation KEB approach as for the initial failure mechanism can be applied to subsequent mechanisms. The mechanism shown in Fig. 6 is very similar to the initial failure mechanism in Fig. 4, and will fail when the limiting force $Q_{\mathrm{u}}^{\mathrm{f}}$ from eq. (18) is approached at the intersection of velocity discontinuities VD3 and VD4. This will happen when the force $Q_{\mathrm{a}}\left(u_{\mathrm{d}}, v_{1}\right)$ from eq. (23), which supports the stable part of the slope, drops to the critical value $Q_{\mathrm{a}}^{\text {cr }}$, determined from the equilibrium of block 3 (and a portion of block 4 directly above it), provided the shear strength on the SPSS is known

$$
Q_{\mathrm{a}}^{\mathrm{cr}}=Q_{\mathrm{u}}^{\mathrm{f}}+\left(\gamma^{\prime} \frac{L_{3}+L_{4}^{\prime}}{2} h\right) \sin \alpha-\int_{0}^{L_{3}} \tau(x) d x
$$
where $L_{3}=\frac{h}{\cos \omega_{\mathrm{opt}} \sin \omega_{\mathrm{opt}}}=h \frac{\chi_{\mathrm{opt}}^{2}+1}{\chi_{\mathrm{opt}}}$ and $L_{4}^{\prime}=h \tan \omega_{\mathrm{opt}}=$
$h \chi_{\mathrm{opt}}$.

Substituting the limiting force $Q_{\mathrm{u}}^{\mathrm{f}}$ from eq. (18) into eq. (25) gives the critical value for the unloading force $Q_{\mathrm{a}}$, indicating initiation of the retrogressive failure above the sliding slab:

$$
\begin{aligned}
Q_{\mathrm{a}}^{\mathrm{cr}}=\frac{\gamma^{\prime} h^{2}}{2}\left(\cos \alpha-\chi_{\mathrm{opt}} \sin \alpha\right)-h \int_{0}^{\chi_{\mathrm{opt}}} s_{\mathrm{u}}(\chi) d \chi & -h \frac{s_{\mathrm{up}}}{\chi_{\mathrm{opt}}} \\
& -\int_{0}^{L_{3}} \tau(x) d x+\tau_{\mathrm{g}} L_{3}
\end{aligned}
$$

where $\tau_{\mathrm{g}}=h \gamma^{\prime} \sin \alpha$. The critical drop of the seabed level, $u_{\mathrm{d}}^{\mathrm{cr}}$, causing the retrogressive failure can then be found from eq. (23) for $Q_{\mathrm{a}}\left(u_{\mathrm{d}}, v_{1}\right)=Q_{\mathrm{a}}^{\mathrm{cr}}$

$$
u_{\mathrm{d}}^{\mathrm{cr}}=\frac{a h-b-\sqrt{(a h-b)^{2}-2 a(c h+d)}}{a}
$$

where parameters $a$ and $b$ are given by eq. (24) and

$$
\begin{aligned}
& c=\frac{s_{\mathrm{up}}-s_{\mathrm{u}}\left(\chi_{\mathrm{VD} 2}\right)}{\chi_{\mathrm{opt}}}+\frac{1}{2} \rho \frac{\chi_{\mathrm{opt}}^{2}}{\chi_{\mathrm{opt}}^{2}+1} v_{1}^{2} \\
& d=\int_{0}^{L_{3}} \tau(x) d x-\tau_{\mathrm{g}} L_{3}
\end{aligned}
$$

Note that for perfectly plastic material $\left(s_{\mathrm{u}}=s_{\mathrm{up}}=\right.$ constant), quasi-static unloading $\left(v_{1}=0\right)$ and average shear strength on SPSS equal to the gravitational shear stress $(d=0)$, eq. (27) gives $u_{\mathrm{d}}^{\mathrm{cr}}=0$, i.e., no drop in the seabed surface is required for the continuing development of spreading failure. 
Fig. 6. Retrogressive failure mechanism.

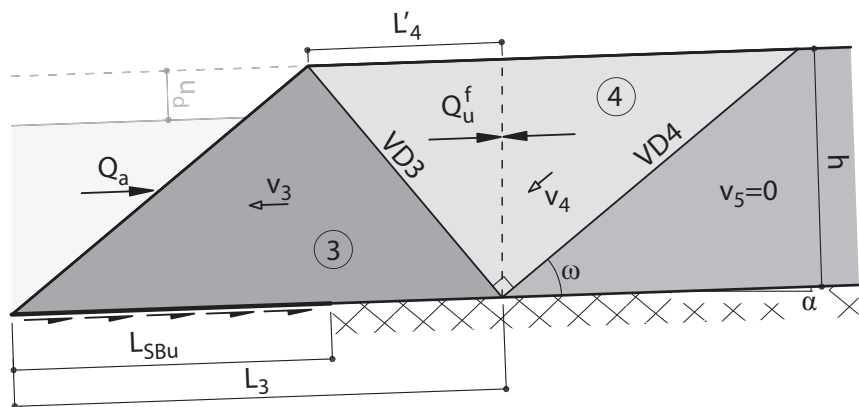

Spreading failure criterion with progressive shear band propagation

From eq. (26) it follows that the critical load for initiating the retrogressive failure is dependent on the shear resistance on the SPSS. If blocks 2,3 , and 4 are assumed to be rigid, limiting equilibrium considerations suggest that the failure would be initiated when the force $Q_{\mathrm{a}}\left(u_{\mathrm{d}}, v_{1}\right)$ from eq. (23) drops to the value determined by the peak strength, $\tau_{\mathrm{p}}$, along the slip surface segment $L_{3}$

$$
\begin{aligned}
Q_{\mathrm{a}}^{\mathrm{LE}}=\frac{\gamma^{\prime} h^{2}}{2}\left(\cos \alpha-\chi_{\mathrm{opt}} \sin \alpha\right)-h \int_{0}^{\chi_{\mathrm{opt}}} s_{\mathrm{u}}(\chi) d \chi & -h \frac{s_{\mathrm{up}}}{\chi_{\mathrm{opt}}} \\
& -\left(\tau_{\mathrm{p}}-\tau_{\mathrm{g}}\right) L_{3}
\end{aligned}
$$

The corresponding critical drop of the seabed level, $u_{\mathrm{d}}^{\mathrm{cr}}$, causing retrogressive failure can be found from eq. (27) by substituting $d=\left(\tau_{\mathrm{p}}-\tau_{\mathrm{g}}\right) L_{3}$.

In reality, however, the pre-failure unloading of the stable part of the slope results in its elastic deformation, which can lead to the progressive uphill propagation of a shear band along the SPSS with subsequent reduction of the shear resistance from its peak value, $\tau_{\mathrm{p}}$, to the residual value, $\tau_{\mathrm{r}}$, along the length of the propagated shear band, $L_{\mathrm{SBu}}$. This results in higher values of the critical force, $Q_{\mathrm{a}}^{\mathrm{cr}}$, than predicted by the limiting equilibrium

$$
Q_{\mathrm{a}}^{\mathrm{EB}}=Q_{\mathrm{a}}^{\mathrm{LE}}+\left(\tau_{\mathrm{p}}-\tau_{\mathrm{r}}\right) \mathrm{L}_{\mathrm{SBu}}
$$

i.e., for the initiation of retrogressive failure less unloading is required. Following Puzrin et al. (2017), the propagation length of such a shear band in the stable zone can be quantified by means of the energy balance approach (Palmer and Rice 1973)

$$
\begin{aligned}
& L_{\mathrm{SBu}}=\frac{Q_{\mathrm{a}}\left(u_{\mathrm{d}}, v_{1}\right)-Q_{0}}{r\left(\tau_{\mathrm{p}}-\tau_{\mathrm{r}}\right)}+L_{\mathrm{cr}} \\
& L_{\mathrm{cr}}=\frac{1}{r} \sqrt{\frac{2 E \bar{\delta} h}{\tau_{\mathrm{p}}-\tau_{\mathrm{r}}}} \\
& r=\frac{h \gamma^{\prime} \sin \alpha-\tau_{\mathrm{r}}}{\tau_{\mathrm{p}}-\tau_{\mathrm{r}}} \\
& \bar{\delta}=\frac{\int_{0}^{\delta_{\mathrm{r}}}\left(\tau-\tau_{\mathrm{r}}\right) d \delta}{\tau_{\mathrm{p}}-\tau_{\mathrm{r}}}
\end{aligned}
$$

where $Q_{0}$ is the initial slope parallel force in the slope, defined using the at rest earth pressure coefficient $K_{0} ; r$ is the gravitational shear stress ratio; $L_{\text {cr }}$ is the critical length for catastrophic SBP; $E$ is the plane strain deformation modulus; and $\bar{\delta}$ is the characteristic displacement (Fig. 3b). In the case where $L_{\mathrm{SBu}}>L_{3}=h$ $\left(\chi_{\text {opt }}^{2}+1\right) / \chi_{\text {opt }}$, the whole base $L_{3}$ of block 3 fully softens to $\tau_{\mathrm{r}}$ and the corresponding critical drop of the seabed level $u_{\mathrm{d}}^{\text {cr }}$ causing the retrogressive failure can be found from eq. (27) by substituting $d=$ $\left(\tau_{\mathrm{r}}-\tau_{\mathrm{g}}\right) L_{3}$. In contrast, for $L_{\mathrm{SBu}}<L_{3}$, only the portion $L_{\mathrm{SBu}}$ of the base $L_{3}$ fully softens, and for the retrogressive failure to take place, a larger drop of the seabed level $u_{\mathrm{d}}$ is needed to overcome the peak strength, $\tau_{\mathrm{p}}$, of the remaining portion $L_{3}-L_{\mathrm{SBu}}$ along the base. This drop can be found from the condition $Q_{\mathrm{a}}\left(u_{\mathrm{d}}, v_{1}\right)=Q_{\mathrm{a}}^{\mathrm{EB}}$. However, because the critical force $Q_{a}^{\mathrm{EB}}$ also depends on the unloading force $Q_{\mathrm{a}}\left(u_{\mathrm{d}}, v_{1}\right)$, the retrogressive condition $Q_{\mathrm{a}}\left(u_{\mathrm{d}}, v_{1}\right)=Q_{\mathrm{a}}^{\mathrm{EB}}$ has to be resolved first with respect to $Q_{\mathrm{a}}\left(u_{\mathrm{d}}, v_{1}\right)$. The spreading failure criterion accounting for progressive SBP can then be formulated in terms of the critical drop of the seabed surface using eq. (23)

$$
u_{\mathrm{d}} \geq u_{\mathrm{d}}^{\mathrm{cr}}=h-\frac{b+\sqrt{b^{2}+2 a Q_{\mathrm{a}}^{\mathrm{cr}}}}{a}
$$

where

$$
Q_{\mathrm{a}}^{\mathrm{cr}}=\frac{r}{r-1}\left[Q_{\mathrm{a}}^{\mathrm{LE}}\left(\tau_{\mathrm{p}}\right)+\left(\tau_{\mathrm{p}}-\tau_{\mathrm{r}}\right) L_{\mathrm{cr}}-\frac{Q_{0}}{r}\right]
$$

Parameters $a$ and $b$ are given by eq. (24), $Q_{\mathrm{a}}^{\mathrm{LE}}$ by eq. (29), and $r$ and $L_{\text {cr }}$ by eq. (31).

Note, that this approach assumes the process zone length to be small compared to the depth of the SPSS. In case the assumption of the small process zone length does not hold, an alternative process zone approach for assessing the shear resistance along the SPSS should be used (e.g., Puzrin and Germanovich 2005; Zhang et al. 2015).

\section{Discussion of spreading failure criterion}

Consider a slope $\alpha$ with thickness of the sliding layer $h$ and effective specific weight $\gamma^{\prime}$. The uniform peak undrained shear strength is assumed to be equal to that in the middle of the layer, calculated as a fraction $k$ of the corresponding vertical effective stress (residual strength is a fraction of the peak one, calculated using the sensitivity $s$ ):

$$
s_{\text {up }}=\frac{1}{2} k h \gamma^{\prime} \quad s_{\text {ur }}=\frac{s_{\text {up }}}{s}
$$

Localized failure along the SPSS requires that its shear strength is lower (a fraction $\Gamma<1$ ) than the shear strength of the adjacent material in the sliding body

$$
\tau_{\mathrm{p}}=\Gamma k h \gamma^{\prime} \quad \tau_{\mathrm{r}}=\frac{\tau_{\mathrm{p}}}{\mathrm{s}}
$$

where $\sigma_{\mathrm{v}}^{\prime}$ is the effective vertical stress.

The softening behaviour of the material in the sliding body is assumed to be exponential (Einav and Randolph 2005), with the characteristic shear strain $X_{\mathrm{r}}$. The characteristic displacement of the SPSS and the stiffness of the sliding body are varied in a parametric study. The values of the parameters used in the parametric study presented below are shown in Table 1 . These values lie within the range typical for Azeri submarine landslides investigated by Gray et al. (2015) and Puzrin et al. (2016). The thickness of the velocity discontinuity within the sliding body $d_{\mathrm{SB}, \mathrm{VD} 2}$ has been chosen of the order of magnitude of $1 \mathrm{~mm}$, typical for the fine-grain sediments.

For quasi-static conditions and the shear stress ratio $r=0\left(\tau_{\mathrm{r}}=\right.$ $\gamma^{\prime} h \sin \alpha$ ), the evolution of the unloading force, $Q_{\mathrm{a}}$, from eq. (23) and Fig. 6 as a function of the drop of the seafloor, $u_{\mathrm{d}}$, is presented in a normalized form as a thin solid black curve with dot markers in Fig. $7 a$. The initial failure forms at $u_{\mathrm{d}}=0$, when the force in the 
Table 1. Parameters of spreading example.

\begin{tabular}{ll}
\hline Parameter & Value \\
\hline$h(\mathrm{~m})$ & 10 \\
$\gamma^{\prime}\left(\mathrm{kN} / \mathrm{m}^{3}\right)$ & 5 \\
$k$ & 0.22 \\
$\Gamma$ & 0.78 \\
$K_{\mathrm{o}}$ & 0.8 \\
$X_{\mathrm{r}}$ & 9 \\
$d_{\mathrm{SB}, \mathrm{VD} 2}(\mathrm{~mm})$ & 1 \\
$s$ & 2 \\
\hline
\end{tabular}

slab at the intersection of VD1 and VD2 drops to $Q_{u}^{f}$ defined from eq. (18). The corresponding initial unloading force $Q_{a}$ is found from eqs. (23) and (24) for $u_{\mathrm{d}}=0$ and $s_{\mathrm{u}}\left(X_{\mathrm{VD} 2}\right)=s_{\mathrm{up}}$. As $u_{\mathrm{d}}$ starts to increase, the unloading force $Q_{\mathrm{a}}$ first also increases due to the rapid softening $s_{\mathrm{u}}\left(\mathrm{X}_{\mathrm{VD2}}\right) \rightarrow s_{\mathrm{ur}}$ along the velocity discontinuity VD2, decreasing coefficient $b$ in eqs. (23) and (24). However, after the VD2 fully softens, the continuously dropping level of the seafloor $u_{\mathrm{d}}$ causes the gradual decrease of the unloading force $Q_{\mathrm{a}}$. For a dynamic case with a constant velocity of block 1 of $v_{1}=2 \mathrm{~m} / \mathrm{s}$, inertia of the failing blocks leads to an increase of the unloading force (shown by a thin black dashed line). This dynamic effect is, however, sufficiently small to justify a quasi-static approximation of the spreading failure criterion.

The two vertical dashed lines in Fig. $7 a$ represent the two extreme cases of the critical force $Q_{a}^{\mathrm{EB}}$ from eq. (30) required to initiate the retrogressive failure of the sliding body. The left line corresponds to the case of $L_{\mathrm{SBu}}=0$, i.e., the peak strength, $\tau_{\mathrm{p}}$, is mobilized along the entire base $L_{3}$ of block 3 , while the right vertical line presents the fully softened case of $L_{S B u} \geq L_{3}$, with only residual strength, $\tau_{\mathrm{r}}$, mobilized along $L_{3}$. Intersection $\mathrm{A}$ of the solid thin black curve (unloading force $Q_{\mathrm{a}}$ ) with the right vertical line represents the value of the minimal critical drop $u_{\mathrm{d}}^{\mathrm{cr}}$ for the case of the shear band propagating far into the stable part of the slope. Intersection B of this curve with the left vertical line represents the value of the minimal critical drop $u_{\mathrm{d}}^{\mathrm{cr}}$ that will cause retrogressive failure even when no SBP into the stable part takes place. In between these two extreme cases, the shear band propagates over a portion of block $3\left(L_{\mathrm{SBu}} \geq L_{3}\right)$ and the critical drop, $u_{\mathrm{d}}^{\text {cr }}$, is found from the spreading failure criterion in eq. (32) as a function of the combination of SBP parameters $E \bar{\delta} /\left(\gamma^{\prime} h^{2}\right)$. As follows from eqs. (31) and (35), the square root of this combination is proportional to the normalized critical length, $L_{\mathrm{cr}} / \mathrm{h}$, of the shear band. In Fig. $7 a$, the critical drop, $u_{\mathrm{d}}^{\mathrm{cr}}$, is presented as horizontal lines for three different values of $E \bar{\delta} /\left(\gamma^{\prime} h^{2}\right)$, and the corresponding values of the unloading force $Q_{\mathrm{a}}$ causing retrogressive failure can be found from the intersection of these horizontal lines with the thin solid black curve. Based on the above considerations, the evolution of the critical load $Q_{\mathrm{a}}^{\mathrm{cr}}$ required for retrogressive failure to take place is depicted by the thick solid black line: above point A it follows the right vertical line, below point $\mathrm{B}$ - the left vertical line; between $A$ and $B$ it follows the $Q_{\mathrm{a}}$ unloading curve.

While in a curved slope it is likely that the initial failure of the sliding body occurs at $r=0$, further spreading may progress into portions of the slope with lower or higher inclination. The corresponding required critical drop for spreading failure depending on the shear stress ratio, $r$, is shown in Fig. 7b. For each value of $r$, the top solid black curve (corresponding to the point A in Fig. 7a) gives the critical drop $u_{\mathrm{d}}^{\text {cr }}$ for the fully softened case of $L_{\mathrm{SBu}}=L_{3}$. Note, that for $r>0$ and the fully softened SPSS, retrogressive failure does not require any drop in the seabed surface. The lower solid black curve presents the case of fully mobilized peak strength $\left(L_{\mathrm{SBu}}=0\right.$, corresponding to point B in Fig. $\left.7 a\right)$. As the shear stress ratio approaches $r \rightarrow-1$, a state is reached (point $C$ ), where even a drop over the full thickness of the sliding body is not sufficient to invoke retrogressive failure, i.e., a stable scarp will form at the top of the slide and the sliding body will detach from it. Intermediate cases of SBP with $L_{\mathrm{SBu}}<L_{3}$ are given by dashed and dotted lines corresponding to three different values of $E \bar{\delta} /\left(\gamma^{\prime} h^{2}\right)$.

\section{Failure at bottom of sliding slab}

In this section the KEB approach is used to formulate the conditions for initial failure at the bottom of the sliding slab, the subsequent evolution of the force in the lower part of the slope as a function of the state of plastic deformation, and the criteria for the ploughing-runout failure.

\section{Initial loading failure mechanism}

The large-deformation loading mechanism (Fig. 8) consists of the downslope moving sliding slab (block 1 ), with the driving force $Q_{1}$, of a heaved soil wedge (block 2) and of the stable part of the slope (block 3 ). The velocities and displacements of blocks 1 and 2 are related by

$$
v_{2}=\cos \omega v_{1} \quad u_{2}=\cos \omega u_{1}
$$

and the corresponding heave of block 2 is

$$
u_{\mathrm{h}}=\sin \omega u_{2}=\cos \omega \sin \omega u_{1}
$$

With increasing deformation, the upper left corner of block 2 will be overhanging and will fail at a certain stage of mechanism deformation. However, for assessing geometry and conditions for initial failure (i.e., small deformations), the potential failure of the corner can be neglected. For subsequent evolution of the mechanism at large deformations the failure of the corner will be included in the analysis.

The work equation can be formulated in the same way as for the unloading mechanism (eq. (6)) and the initial volumes of blocks 1 and 2 are given in eq. (7). The volume of the material crossing the velocity discontinuity VD1 is

$$
\dot{V}_{\mathrm{sl}}=h v_{1} \quad V_{\mathrm{sl}}=\int h v_{1} d t=h u_{1}
$$

and is equal to the area of the grey smeared shear zone in Fig. 8. The rate of external work with respect to the gravity acting on blocks 1 and 2 and the driving force $Q_{1}$ is given by

$$
\begin{aligned}
\dot{W}_{\mathrm{e}}\left(Q_{l}, v_{1}\right) & +\dot{W}_{\mathrm{e}}\left(G_{1}^{\prime}, v_{1}\right)+\dot{W}_{\mathrm{e}}\left(G_{2}^{\prime}, v_{2}\right)=Q_{1} v_{1} \\
& +\left(V_{10}-V_{\mathrm{sl}}\right) \gamma^{\prime} v_{1} \sin \alpha-\left(V_{20}+V_{\mathrm{sl}}\right) \gamma^{\prime} v_{2} \sin (\omega-\alpha)
\end{aligned}
$$

The dissipation rates along the velocity discontinuities are formulated in analogy to the unloading mechanism

$$
\begin{aligned}
\dot{D}_{\mathrm{iSPSS}}+\dot{D}_{\mathrm{iVD} 2}+\dot{D}_{\mathrm{iVD} 1}=\int_{-X}^{0} \tau(x) v_{1} d x+s_{\mathrm{u}}\left(\chi_{\mathrm{VD} 2}\right) & \frac{h}{\sin \omega} v_{2} \\
& +h v_{1} \int_{0}^{\tan \omega} s_{\mathrm{u}}(\chi) d \chi
\end{aligned}
$$

The optimization of the mechanism geometry results in the optimal angle $\omega_{\text {opt }}$, which is the same as for the unloading mechanism given by eq. (15). Using the condition described by eq. (17) and in analogy to the unloading failure mechanism, the threshold 
Fig. 7. Representation of the spreading failure criterion: $(a)$ normalized failure force $Q_{\mathrm{a}} / Q_{0}$ depending on the normalized drop $u_{\mathrm{d}} / \mathrm{h}$ and required normalized force for the formation of spreading failure for different $E \bar{\delta} /\left(\gamma^{\prime} h^{2}\right)$ (dashed coloured lines) at the shear stress ratio $r=0$ $\left(\alpha=4.9^{\circ}\right)$; $(b)$ normalized critical drop $u_{\mathrm{d}}^{\mathrm{cr}} / h$ depending on the shear stress ratio, $r$.

normalized failure force $\mathrm{Q}_{\mathrm{a}} / \mathrm{Q}_{0}$

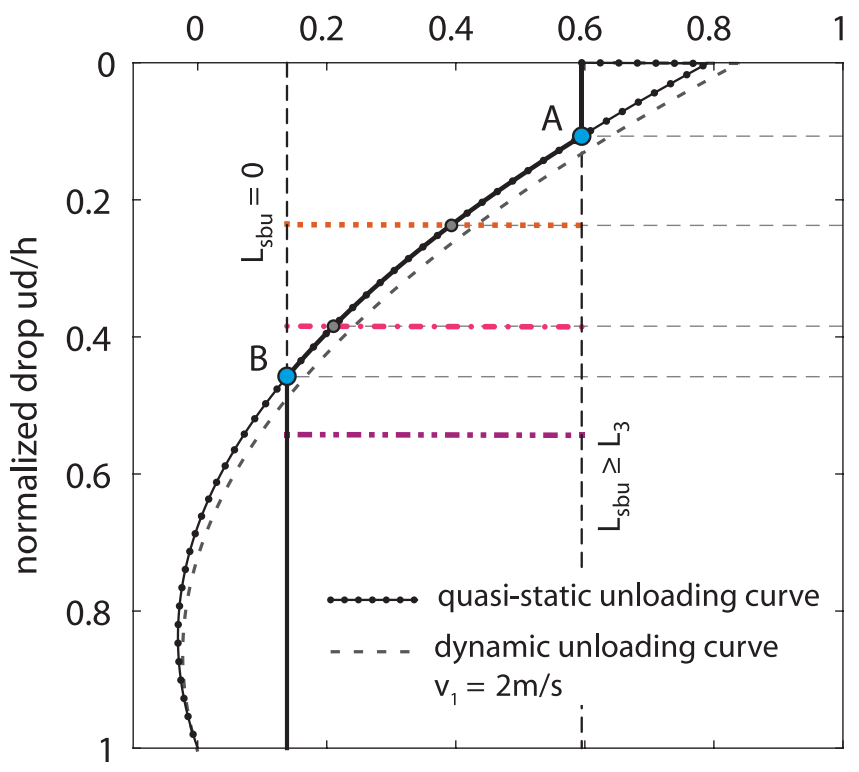

(a)

Fig. 8. Kinematics of large-deformation loading mechanism.

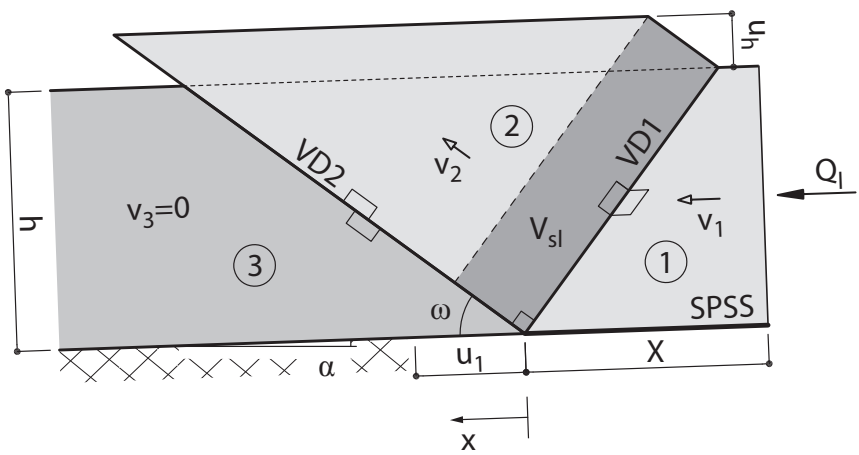

for initial failure at the bottom of the sliding slab can be expressed by the limiting loading failure force

$$
Q_{1}^{\mathrm{f}}=\frac{\gamma^{\prime} h^{2}}{2}\left[\cos \alpha-\sin \alpha\left(\frac{1-\chi_{\mathrm{opt}}^{2}}{\chi_{\mathrm{opt}}}\right)\right]+h\left[\int_{0}^{\chi_{\mathrm{opt}}} s_{\mathrm{u}}(\chi) d \chi+\frac{s_{\mathrm{up}}}{\chi_{\mathrm{opt}}}\right]
$$

\section{Evolution of force acting on stable part of slope}

To describe the evolution of the slope parallel force $Q_{p}$, which is acting on the stable part of the slope (i.e., block 3), it is essential to include large deformations and geometric nonlinearities into the analysis. Similar to the unloading mechanism, the material crossing velocity discontinuity VD1 and increasing the volume of block 2 has to be taken into account. The failure of the soil at the overhanging corner of block 2 and the corresponding loss of volume of block 2 should also be taken into account (Fig. 9). In general, the breaking of soil from the overhanging corner of block 2 can be assessed by means of upper bound limit analysis, leading to a mechanism with an increasing number of failed blocks on the seafloor. This mechanism, however, can be drastically simplified by replacing the break-

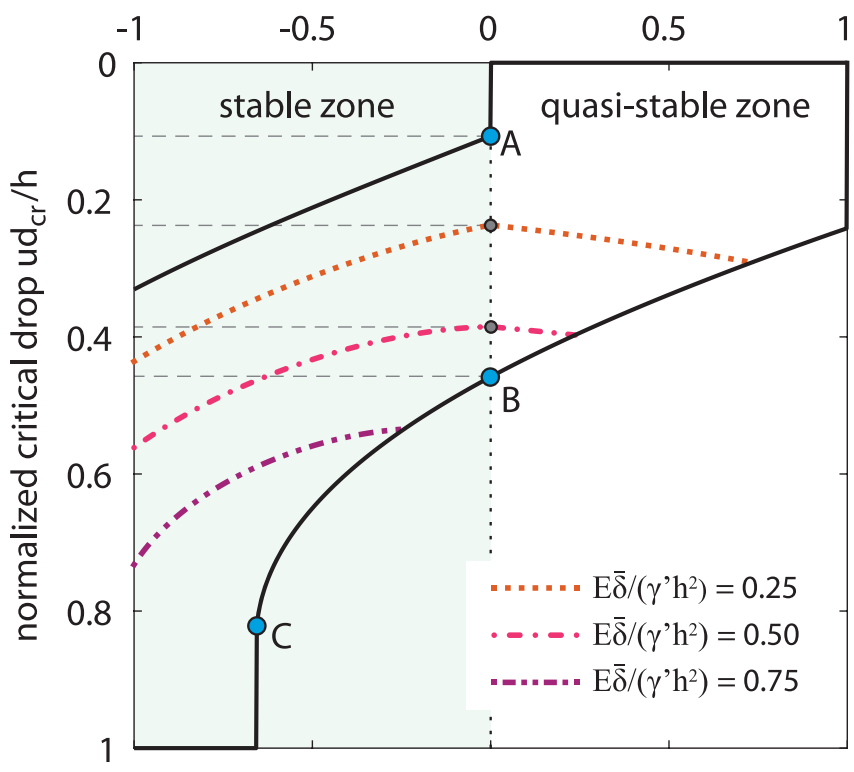

(b)

Fig. 9. Kinematics of loading mechanism.

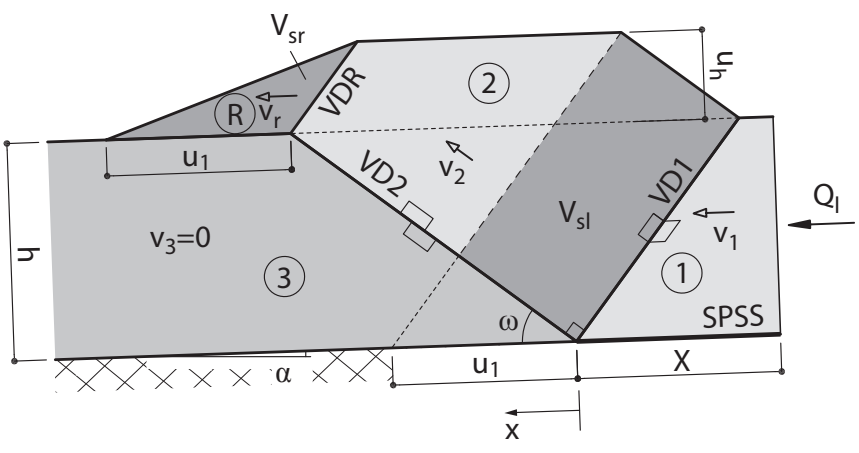

ing of discrete blocks with continuous shearing of the soil, which crosses velocity discontinuity VDR and forms the new block R. It can be shown that a good fit between the general and simplified mechanisms can be achieved by choosing a shearing angle as $\omega_{\mathrm{r}}=\omega$, resulting in the kinematic relation $v_{\mathrm{r}}=v_{1}$, and the volume of the sheared material crossing velocity discontinuity VDR is given by

$$
\dot{V}_{\text {sr }}=u_{\mathrm{h}} v_{1} \quad V_{\mathrm{sr}}=\int u_{\mathrm{h}} v_{1} d t=\int u_{\mathrm{h}} d u_{1}=\frac{u_{\mathrm{h}} u_{1}}{2}
$$

where $u_{\mathrm{h}}$ is the heave of the seabed surface.

As the slab keeps sliding and the new material is sheared into block $R$, it moves over the top of the stable block 3 with velocity $v_{\mathrm{r}}=v_{1}$, overcoming resistance $s_{\mathrm{r}}$ on the interface between blocks $\mathrm{R}$ and 3. This resistance, however, is likely to be very low due to the intercalation of the seawater between the original seabed and the overflowing sheared material. In the following, $s_{\mathrm{r}}=0$ is assumed.

The rate of kinetic energy for the evolving mechanism can be calculated from the energy balance equation as a difference 


$$
\begin{aligned}
\dot{\mathrm{E}}_{\mathrm{kin}}=\dot{W}_{\mathrm{e}}-\dot{D}_{\mathrm{i}}=\dot{W}_{\mathrm{e}}\left(Q_{1}, v_{1}\right)+\dot{W}_{\mathrm{e}}\left(G_{1}^{\prime}, v_{1}\right)+\dot{W}_{\mathrm{e}}\left(G_{2}^{\prime}, v_{2}\right) \\
+\dot{W}_{\mathrm{e}}\left(G_{\mathrm{r}}^{\prime}, v_{\mathrm{r}}\right)-\left[\dot{D}_{\mathrm{iSPSS}}+\dot{D}_{\mathrm{iVD} 1}+\dot{D}_{\mathrm{iVD} 2}+\dot{D}_{\mathrm{iVD} 3}\right]
\end{aligned}
$$

between the external work rates

$$
\begin{array}{r}
\dot{W}_{\mathrm{e}}\left(Q_{1}, v_{1}\right)+\dot{W}_{\mathrm{e}}\left(G_{1}^{\prime}, v_{1}\right)+\dot{W}_{\mathrm{e}}\left(G_{2}^{\prime}, v_{2}\right)+\dot{W}_{\mathrm{e}}\left(G_{\mathrm{r}}^{\prime}, v_{\mathrm{r}}\right) \\
=Q_{1} v_{1}+\left(V_{10}-V_{\mathrm{sl}}\right) \gamma^{\prime} v_{1} \sin \alpha-\left(V_{20}+V_{\mathrm{sl}}-V_{\mathrm{sr}}\right) \gamma^{\prime} v_{2} \sin (\omega-\alpha) \\
+V_{\mathrm{sr}} \gamma^{\prime} v_{\mathrm{r}} \sin \alpha
\end{array}
$$

The same rate of kinetic energy can also be calculated by differentiating the total kinetic energy of the three blocks $-1,2$, and $\mathrm{R}$ - with respect to time

$$
\begin{array}{r}
\dot{E}_{\text {kin }}=\frac{\partial\left\langle(1 / 2) \rho\left\{\left(V_{10}-V_{\mathrm{sl}}\right)+\left[1 /\left(\chi_{\mathrm{opt}}^{2}+1\right)\right]\left(V_{20}+V_{\mathrm{sl}}-V_{\mathrm{sr}}\right)+V_{\mathrm{sr}}\right\} v_{1}^{2}\right\rangle}{\partial t}=\rho\left\{\left[V_{10}+V_{20}\left(\frac{1}{\chi_{\mathrm{opt}}^{2}+1}\right)+\left(V_{\mathrm{sr}}-V_{\mathrm{sl}}\right)\left(\frac{\chi_{\mathrm{opt}}^{2}}{\chi_{\mathrm{opt}}^{2}+1}\right)\right] \dot{v}_{1}\right. \\
\left.+\frac{1}{2}\left(\dot{V}_{\mathrm{sr}}-\dot{V}_{\mathrm{sl}}\right)\left(\frac{\chi_{\mathrm{opt}}^{2}}{\chi_{\mathrm{opt}}^{2}+1}\right) v_{1}\right\} v_{1}
\end{array}
$$

Substituting eqs. (44)-(46) into the energy balance eq. (43) provides the expression relating the slab force $Q_{1}$ to the acceleration, $\dot{v}_{1}$, and velocity, $v_{1}$, of the mechanism

$$
\begin{array}{r}
Q_{1}=\frac{1}{2} \rho\left(\dot{V}_{\mathrm{sr}}-\dot{V}_{\mathrm{sl}}\right) \frac{\chi_{\mathrm{opt}}^{2}}{\chi_{\mathrm{opt}}^{2}+1} v_{1}+\rho\left[V_{10}+V_{20} \frac{1}{\chi_{\mathrm{opt}}^{2}+1}+\left(V_{\mathrm{sr}}-V_{\mathrm{sl}}\right) \frac{\chi_{\mathrm{opt}}^{2}}{\chi_{\mathrm{opt}}^{2}+1}\right] \dot{v}_{1}+\int_{0}^{\mathrm{X}} \tau(x) d x+h \frac{s_{\mathrm{u}}\left(\chi_{\mathrm{vD} 2}\right)}{\chi_{\mathrm{opt}}}+\left(h+u_{\mathrm{h}}\right) \int_{0}^{\chi_{\mathrm{opt}}} s_{\mathrm{ul}}(\chi) d \chi \\
-\gamma^{\prime}\left[\left(V_{10}+V_{20}\right) \sin \alpha-\left(V_{20}+V_{\mathrm{sl}}-V_{\mathrm{sr}} \frac{\chi_{\mathrm{opt}}\left(\cos \alpha+\chi_{\mathrm{opt}} \sin \alpha\right)}{\chi_{\mathrm{opt}}^{2}+1}\right]\right.
\end{array}
$$

Formulating the equation of motion in the slope parallel direction requires inertia forces $I_{1}, I_{2}$, and $I_{\mathrm{r}}$, which can be found from time derivatives of the momentum of blocks 1,2 , and $\mathrm{R}$, respectively

$$
\begin{aligned}
& I_{1}=\frac{\partial\left[\rho\left(V_{10}-V_{\mathrm{sl}}\right) v_{1}\right]}{\partial t}=\rho\left(V_{10}-V_{\mathrm{sl}}\right) \dot{v}_{1}-\rho \dot{V}_{\mathrm{sl}} v_{1} \\
& I_{2}=\frac{\partial\left[\rho\left(V_{20}+V_{\mathrm{sl}}-V_{\mathrm{sr}}\right) v_{2}\right]}{\partial t}=\rho\left(V_{20}+V_{\mathrm{sl}}-V_{\mathrm{sr}}\right) \frac{1}{\sqrt{\chi_{\mathrm{opt}}^{2}+1}} \dot{v}_{1}+\rho\left(\dot{V}_{\mathrm{sl}}-\dot{V}_{\mathrm{sr}}\right) \frac{1}{\sqrt{\chi_{\mathrm{opt}}^{2}+1}} v_{1} \\
& I_{\mathrm{r}}=\rho V_{\mathrm{sr}} \dot{v}_{1}+\rho \dot{V}_{\mathrm{sr}} v_{1}
\end{aligned}
$$

The equation of motion in slope parallel direction is then given by

$$
\begin{aligned}
Q_{\mathrm{p}}=Q_{1}-\int_{0}^{X} \tau(x) d x-I_{1}-I_{2} \frac{1}{\sqrt{\chi_{\mathrm{opt}}^{2}+1}}-I_{\mathrm{r}} \\
+\gamma^{\prime}\left(V_{10}+V_{20}\right) \sin \alpha
\end{aligned}
$$

which after substitution of the slab force $Q_{1}$ from eq. (47) and inertia forces from eq. (48) provides the expression for the force $Q_{\mathrm{p}}$ acting on the stable part of the slope (see Fig. 10) as a function of the heave of the seabed surface, $u_{\mathrm{h}}$, the velocity of the mechanism, $v_{1}$, slope geometry, $\alpha$, and shear strength of the soil, $s_{\mathrm{u}}$

$$
\begin{aligned}
& Q_{\mathrm{p}}\left(u_{\mathrm{d}}, v_{1}\right)=\gamma^{\prime}\left[\left(\frac{h^{2}}{2}+h u_{\mathrm{h}}-\frac{u_{\mathrm{h}}{ }^{2}}{2}\right)\left(\cos \alpha+\chi_{\mathrm{opt}} \sin \alpha\right)\right] \\
& +h \frac{s_{\mathrm{u}}\left(\chi_{\mathrm{VD} 2}\right)}{\chi_{\mathrm{opt}}}+\left(h+u_{\mathrm{h}}\right) \int_{0}^{\chi_{\mathrm{opt}}} s_{\mathrm{u}}(\chi) d \chi+\frac{1}{2} \rho\left(h-u_{\mathrm{h}}\right) \frac{\chi_{\mathrm{opt}}^{2}}{\chi_{\mathrm{opt}}^{2}+1} v_{1}^{2}
\end{aligned}
$$

\section{Ploughing failure criterion}

The mechanism in Fig. 11 is very similar to the initial failure mechanism in Fig. 8, and will fail when the force acting on block 3 reaches its critical value $Q_{\mathrm{p}}^{\mathrm{cr}}$. This critical force is larger than the one for the first failure mechanism in Fig. 8, because by the time the second failure mechanism develops, there is an overflow of material from block 2 over block 4 , increasing its volume

$$
V_{30}=\frac{h^{2}}{2 \cos \omega \sin \omega} \quad V_{40}=V_{30}+V_{\mathrm{sr}}=\frac{h^{2}+u_{\mathrm{h}}^{2}}{2 \cos \omega \sin \omega}
$$

In addition, because of this overflow, the length of the velocity discontinuity VD3 is larger than that of VD1 in the initial mechanism, resulting in a higher rate of the volume crossing this discontinuity:

$$
\dot{V}_{\mathrm{sl}}=\frac{h+u_{\mathrm{h}}}{\cos \omega} v_{4}=\left(h+u_{\mathrm{h}}\right) v_{3}
$$


Fig. 10. Dynamic equilibrium loading mechanism.

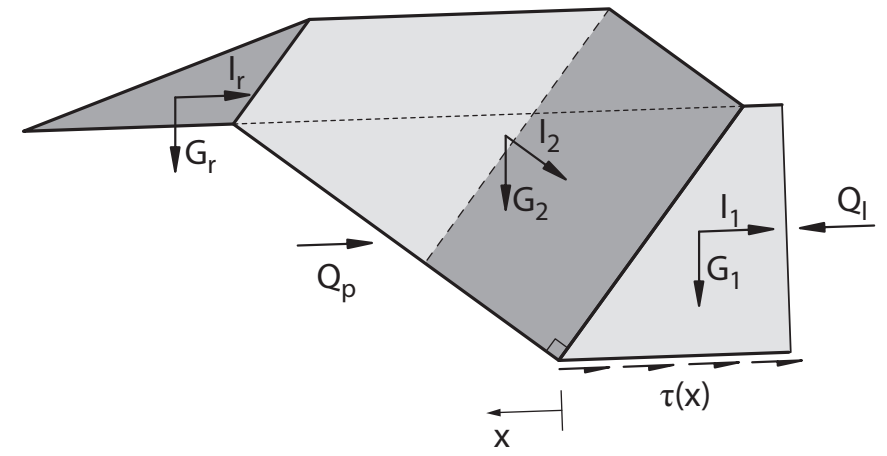

Following the principles of limit analysis, the condition for initial (static) failure of the second mechanism is determined by the energy balance equation for blocks 3 and 4

$$
\dot{\mathrm{E}}_{\mathrm{kin}}\left(u_{3}=0, \omega=\omega_{\text {opt }}\right)=\dot{W}_{\mathrm{e}}-\dot{D}_{i}=0
$$

The rate of external work with respect to the gravity acting on blocks 3 and 4 and the critical driving force $Q_{\mathrm{p}}^{\mathrm{cr}}$ is given by

$$
\begin{aligned}
\dot{W}_{\mathrm{e}}\left(Q_{\mathrm{p}}^{\mathrm{cr}}, v_{3}\right) & +\dot{W}_{\mathrm{e}}\left(G_{3}^{\prime}, v_{3}\right)+\dot{W}_{\mathrm{e}}\left(G_{4}^{\prime}, v_{4}\right) \\
& =Q_{\mathrm{p}}^{\mathrm{cr}} v_{3}+V_{30} \gamma^{\prime} v_{3} \sin \alpha-V_{40} \gamma^{\prime} v_{4} \sin \left(\omega_{\text {opt }}-\alpha\right)
\end{aligned}
$$

The dissipation rates along the velocity discontinuities are formulated in analogy to the first failure mechanism

$$
\begin{aligned}
\dot{D}_{\mathrm{iSPSS}}+\dot{D}_{\mathrm{iVD} 4}+\dot{D}_{\mathrm{iVD} 3} & =v_{3} \int_{0}^{L_{3}} \tau(x) d x \\
& +s_{\mathrm{u}}\left(\chi_{\mathrm{VD} 4}=0\right) \frac{h}{\sin \omega_{\mathrm{opt}}} v_{4}+\dot{V}_{\mathrm{sl}} \int_{0}^{\chi_{\mathrm{opt}}} s_{\mathrm{u}}(\chi) d \chi
\end{aligned}
$$

where $L_{3}=\frac{h}{\cos \omega_{\mathrm{opt}} \sin \omega_{\mathrm{opt}}}=h \frac{\chi_{\mathrm{opt}}^{2}+1}{\chi_{\mathrm{opt}}}$.

Substituting eqs. (54) and (55) into eq. (53) gives the value of the critical driving force, $Q_{\mathrm{p}}^{\mathrm{cr}}$, causing the initiation of the second (and all subsequent) ploughing failure mechanisms

$$
\begin{aligned}
Q_{\mathrm{p}}^{\mathrm{cr}}=\frac{\gamma^{\prime} h^{2}}{2}( & \left.\cos \alpha+\chi_{\mathrm{opt}} \sin \alpha\right)+\frac{\gamma^{\prime} u_{\mathrm{h}}^{2}}{2}\left(\cos \alpha-\frac{\sin \alpha}{\chi_{\mathrm{opt}}}\right) \\
& +\left(h+u_{\mathrm{h}}\right) \int_{0}^{\chi_{\mathrm{opt}}} s_{\mathrm{u}}(\chi) d \chi+h \frac{s_{\mathrm{up}}}{\chi_{\mathrm{opt}}}+\int_{0}^{L_{3}} \tau(x) d x-\tau_{\mathrm{g}} L_{3}
\end{aligned}
$$

where $\tau_{\mathrm{g}}=h \gamma^{\prime} \sin \alpha$. This second mechanism will develop when the force $Q_{\mathrm{p}}\left(u_{\mathrm{h}}, v_{1}\right)$ from eq. (50), which loads the stable part of the slope, reaches the critical value $Q_{\mathrm{p}}^{\mathrm{cr}}$ from eq. (56). This takes place when the heave of the seabed level $u_{\mathrm{h}}^{\mathrm{cr}}$ reaches its critical value

$$
u_{\mathrm{h}}^{\mathrm{cr}}=\frac{b-\sqrt{b^{2}-4 a(c h+d)}}{2 a}
$$

where

$$
\begin{aligned}
& a=\gamma^{\prime}\left(\cos \alpha-\sin \alpha \frac{1-\chi_{\mathrm{opt}}^{2}}{2 \chi_{\mathrm{opt}}}\right) \\
& b=\gamma^{\prime} h\left(\cos \alpha+\chi_{\mathrm{opt}} \sin \alpha\right)-\frac{1}{2} \rho \frac{\chi_{\mathrm{opt}}^{2}}{\chi_{\mathrm{opt}}^{2}+1} v_{1}^{2} \\
& c=\frac{s_{\mathrm{up}}-s_{\mathrm{u}}\left(\chi_{\mathrm{VD} 4}\right)}{\chi_{\mathrm{opt}}}-\frac{1}{2} \rho \frac{\chi_{\mathrm{opt}}^{2}}{\chi_{\mathrm{opt}}^{2}+1} v_{1}^{2} \\
& d=\int_{0}^{L_{3}} \tau(x) d x-\tau_{\mathrm{g}} L_{3}
\end{aligned}
$$

Note that similar to spreading, in the case of a perfectly plastic material $\left(s_{\mathrm{u}}=s_{\mathrm{up}}=\right.$ constant), quasi-static loading $\left(v_{1}=0\right)$ and average shear strength on the SPSS equal to the gravitational shear stress $(d=0)$, eq. (57) gives $u_{\mathrm{h}}^{\mathrm{cr}}=0$, i.e., no heave in the seabed surface is required for the continuing ploughing. From eq. (56) it can be seen that the failure load causing ploughing depends on the shear resistance on the SPSS. If blocks 2, 3, and 4 are assumed to be rigid plastic, limiting equilibrium considerations suggest that the failure would be initiated when the force $Q_{\mathrm{p}}\left(u_{\mathrm{h}}, v_{1}\right)$ from eq. (50) drops to the value determined by the peak strength, $\tau_{\mathrm{p}}$, along the slip surface segment $L_{3}$

$$
\begin{aligned}
Q_{\mathrm{p}}^{\mathrm{LE}}=\frac{\gamma^{\prime} h^{2}}{2}(\cos \alpha & \left.+\chi_{\mathrm{opt}} \sin \alpha\right)+\frac{\gamma^{\prime} u_{\mathrm{h}}^{2}}{2}\left(\cos \alpha-\frac{\sin \alpha}{\chi_{\mathrm{opt}}}\right) \\
& +\left(\tau_{\mathrm{p}}-\tau_{\mathrm{g}}\right) L_{3}+\left(h+u_{\mathrm{h}}\right) \int_{0}^{\chi_{\mathrm{opt}}} s_{\mathrm{u}}(\chi) d \chi+h \frac{s_{\mathrm{up}}}{\chi_{\mathrm{opt}}}
\end{aligned}
$$

The critical heave of the seabed level, $u_{\mathrm{h}}^{\mathrm{cr}}$, causing ploughing is then defined from eq. (57), where $d=\left(\tau_{\mathrm{p}}-\tau_{\mathrm{g}}\right) L_{3}$.

In reality, however, the pre-failure loading of the stable part of the slope results in its elastic deformation, which can lead to progressive downhill propagation of a shear band along the SPSS with subsequent reduction of the shear resistance from its peak value, $\tau_{\mathrm{p}}$, to the residual value, $\tau_{\mathrm{r}}$, along the length of the propagated shear band $L_{\mathrm{SB} 1}$. This results in lower values of the critical force $Q_{\mathrm{p}}^{\mathrm{cr}}$ than predicted by the limiting equilibrium

$$
Q_{\mathrm{p}}^{\mathrm{EB}}=Q_{\mathrm{p}}^{\mathrm{LE}}-\left(\tau_{\mathrm{p}}-\tau_{\mathrm{r}}\right) L_{\mathrm{SBl}}
$$

i.e., for the initiation of the ploughing smaller loads are required. Following Puzrin (2016), the propagation length of such a shear band in the stable zone can be quantified by means of the energy balance approach (Palmer and Rice 1973)

$$
L_{\mathrm{SBl}}=L_{\mathrm{cr}}-\frac{Q_{\mathrm{p}}\left(u_{\mathrm{h}}, v_{1}\right)-Q_{0}}{r\left(\tau_{\mathrm{p}}-\tau_{\mathrm{r}}\right)}
$$

where $Q_{0}$ is the initial slope parallel force in the slope. The critical length for catastrophic SBP $L_{\mathrm{cr}}$ and the gravitational shear stress ratio, $r$, are given by eq. (31). In the case where $L_{S B l}>L_{3}=$ $h \frac{\chi_{\mathrm{opt}}^{2}+1}{\chi_{\mathrm{opt}}}$, the whole base $L_{3}$ of block 3 fully softens to $\tau_{\mathrm{r}}$ and the corresponding critical heave of the seabed level, $u_{\mathrm{h}}^{\mathrm{cr}}$, causing ploughing can be found from eq. (57) by substituting $d=\left(\tau_{\mathrm{r}}-\tau_{\mathrm{g}}\right) L_{3}$. In contrast, for $L_{\mathrm{SB} 1}<L_{3}$, only the portion $L_{\mathrm{SB} 1}$ of the base $L_{3}$ fully softens, and a larger heave of the seabed $u_{\mathrm{h}}$ is needed to overcome the peak strength, $\tau_{\mathrm{p}}$, of the remaining portion $L_{3}-$ $L_{\mathrm{SB} 1}$ of the base. This heave can be found from the condition $Q_{\mathrm{p}}\left(u_{\mathrm{h}}, v_{1}\right)=Q_{\mathrm{p}}^{\mathrm{EB}}$, where the critical force $Q_{\mathrm{p}}^{\mathrm{EB}}$ also depends on the loading force $Q_{\mathrm{p}}\left(u_{\mathrm{h}}, v_{1}\right)$. After resolving the ploughing condition 
Fig. 11. Critical loading force for initiation of second failure mechanism.

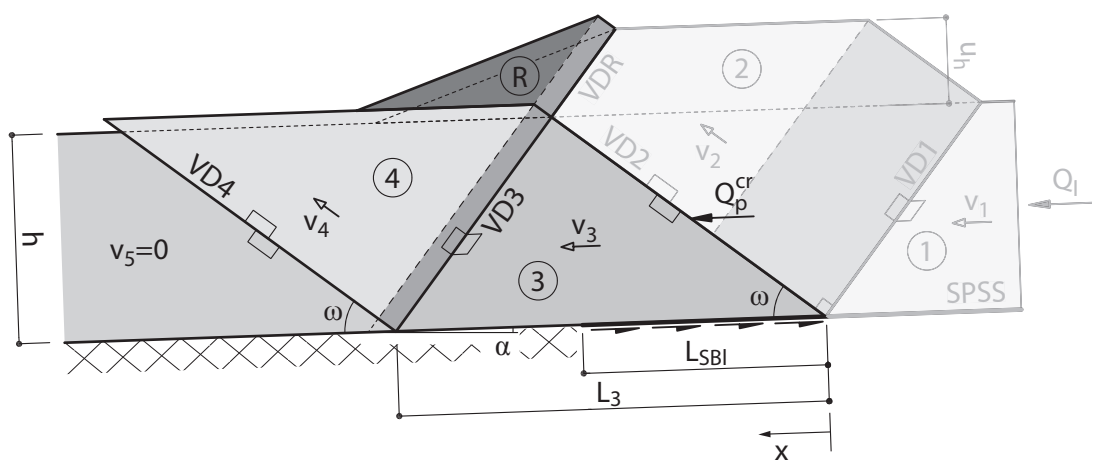

Fig. 12. Representation of ploughing failure criterion: $(a)$ normalized failure force $Q_{\mathrm{p}} / Q_{0}$ depending on the normalized heave $u_{\mathrm{h}} / \mathrm{h}$ and required normalized force for the formation of ploughing failure for different $E \bar{\delta} /\left(\gamma^{\prime} h^{2}\right)$ values (dashed coloured lines) at shear stress ratio, $r=0\left(\alpha=4.9^{\circ}\right) ;(b)$ normalized critical heave, $u_{\mathrm{h}}^{\mathrm{cr}} / h$, depending on shear stress ratio, $r$.

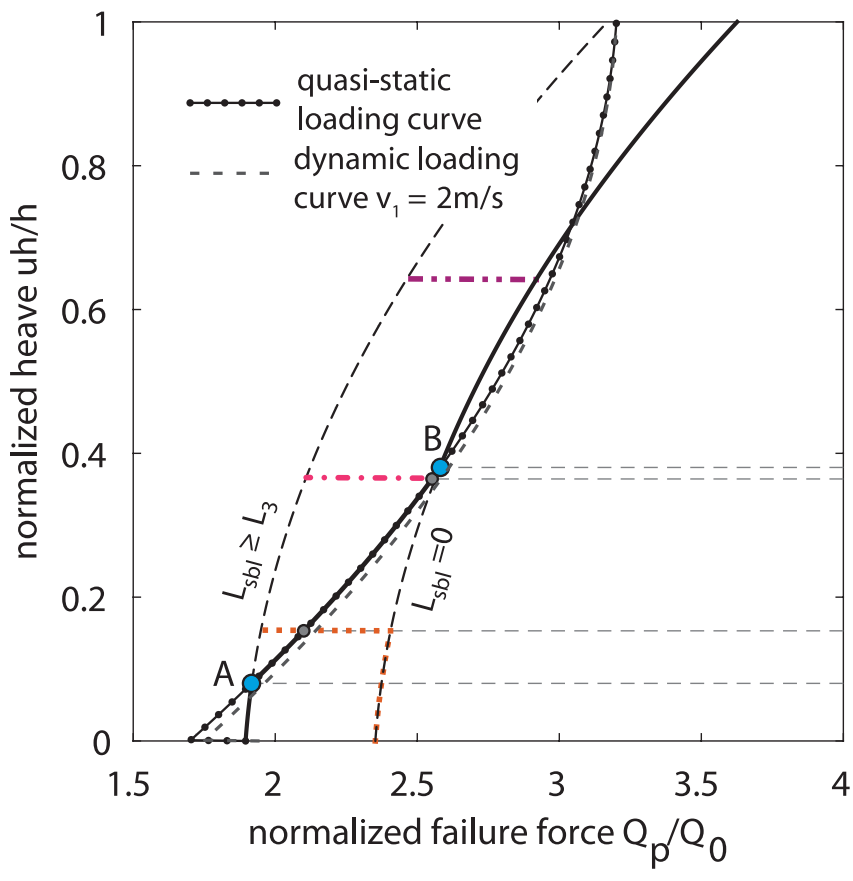

(a)

$Q_{\mathrm{a}}\left(u_{\mathrm{d}}, v_{1}\right)=Q_{\mathrm{a}}^{\mathrm{EB}}$ with respect to $Q_{\mathrm{p}}\left(u_{\mathrm{h}}, v_{1}\right)$, the critical heave of the seabed surface can be found from the following quadratic equation:

$$
Q_{\mathrm{p}}\left(u_{\mathrm{h}}^{\mathrm{cr}}\right)=\frac{r}{r-1}\left[Q_{\mathrm{p}}^{\mathrm{LE}}\left(u_{\mathrm{h}}^{\mathrm{cr}}\right)-\left(\tau_{\mathrm{p}}-\tau_{\mathrm{r}}\right) L_{\mathrm{cr}}-\frac{Q_{0}}{r}\right]
$$

derived using eqs. (50) and (59)-(61). Parameters $r$ and $L_{\text {cr }}$ are given by eq. (31). Note that this approach assumes the process zone length to be small compared to the depth of the SPSS.

\section{Discussion on ploughing criterion}

Similar to the spreading case in Fig. 7, a limited parametric study (with the same set of parameters from Table 1) is used here to discuss the ploughing criteria. Compared to the spreading case in Fig. 7, the range of the combination of SBP parameters $E \bar{\delta} /\left(\gamma^{\prime} h^{2}\right)$ in Fig. 12 has been shifted towards higher values, to obtain the complete range of the normalized critical heaves. For quasi-static conditions and the shear stress ratio $r=0\left(\tau_{\mathrm{r}}=\gamma^{\prime} h \sin \alpha\right)$, the evolution of the loading force $Q_{p}$ from eq. (50) and Fig. 10 is presented in

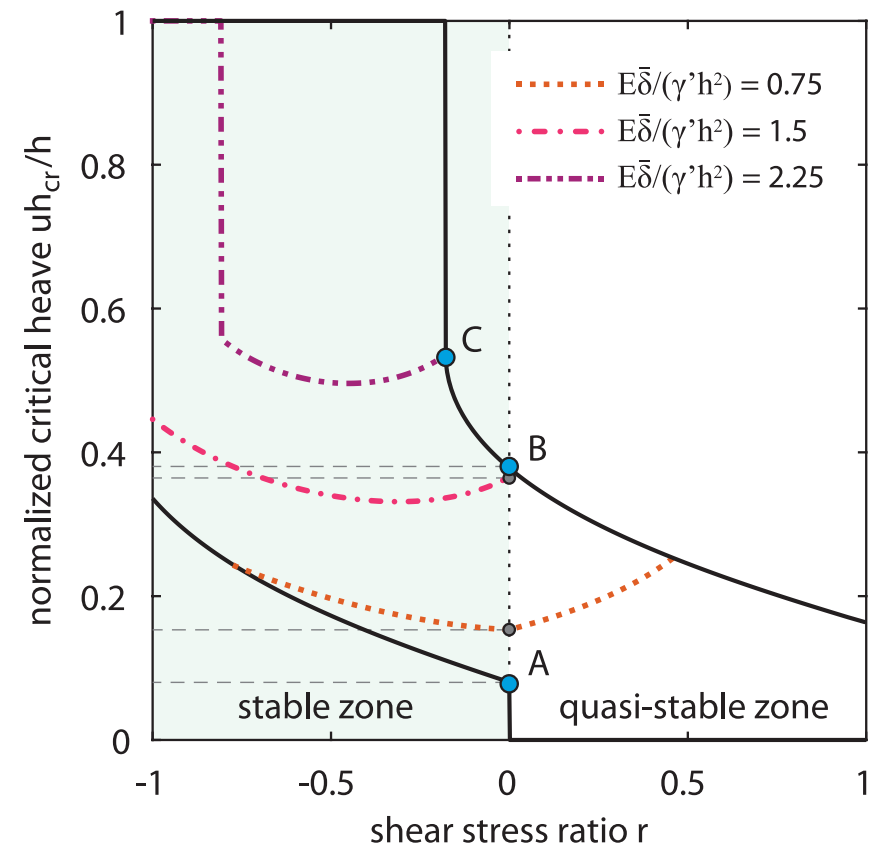

(b)

a normalized form as a function of the heave of the seafloor $u_{\mathrm{h}}$ (thin solid black line with dot markers in Fig. 12a). The initial failure forms at $u_{\mathrm{h}}=0$, when the force in the slab at the intersection of VD1 and VD2 reaches $Q_{1}^{\mathrm{f}}$ defined by eq. (41). As $u_{\mathrm{h}}$ starts to increase, the loading force $Q_{\mathrm{a}}$ first decreases due to the rapid softening $s_{\mathrm{u}}\left(\mathrm{X}_{\mathrm{VD} 2}\right) \rightarrow s_{\mathrm{ur}}$ along the velocity discontinuity VD2. Further deformation leads to increase of the normalized loading force caused by the geometric hardening of the sliding body according to eq. (50). Similar to spreading, for a dynamic case with a constant velocity of block 1 of $v_{1}=2 \mathrm{~m} / \mathrm{s}$, inertia of the failing blocks leads to an increase of the loading force (dashed line), but this dynamic effect is sufficiently small to justify a quasi-static approximation of the ploughing failure criterion.

The left and right thin dashed curves in Fig. 12a represent the two extreme cases of the critical force $Q_{\mathrm{p}}^{\mathrm{EB}}$ from eq. (60), which are required to initiate ploughing in the sliding body. The curved shape results here from the fact that in contrast to spreading, not only the loading force $Q_{\mathrm{p}}$ but also its critical failure limit $Q_{\mathrm{p}}^{\mathrm{EB}}$ are functions of the heave $u_{\mathrm{h}}$, which is a result of the material being deposited on top of the subsequent failure mechanism. The right 
Fig. 13. Submarine landslide evolution: numerical integration of kinematic energy balance approach for the example case.

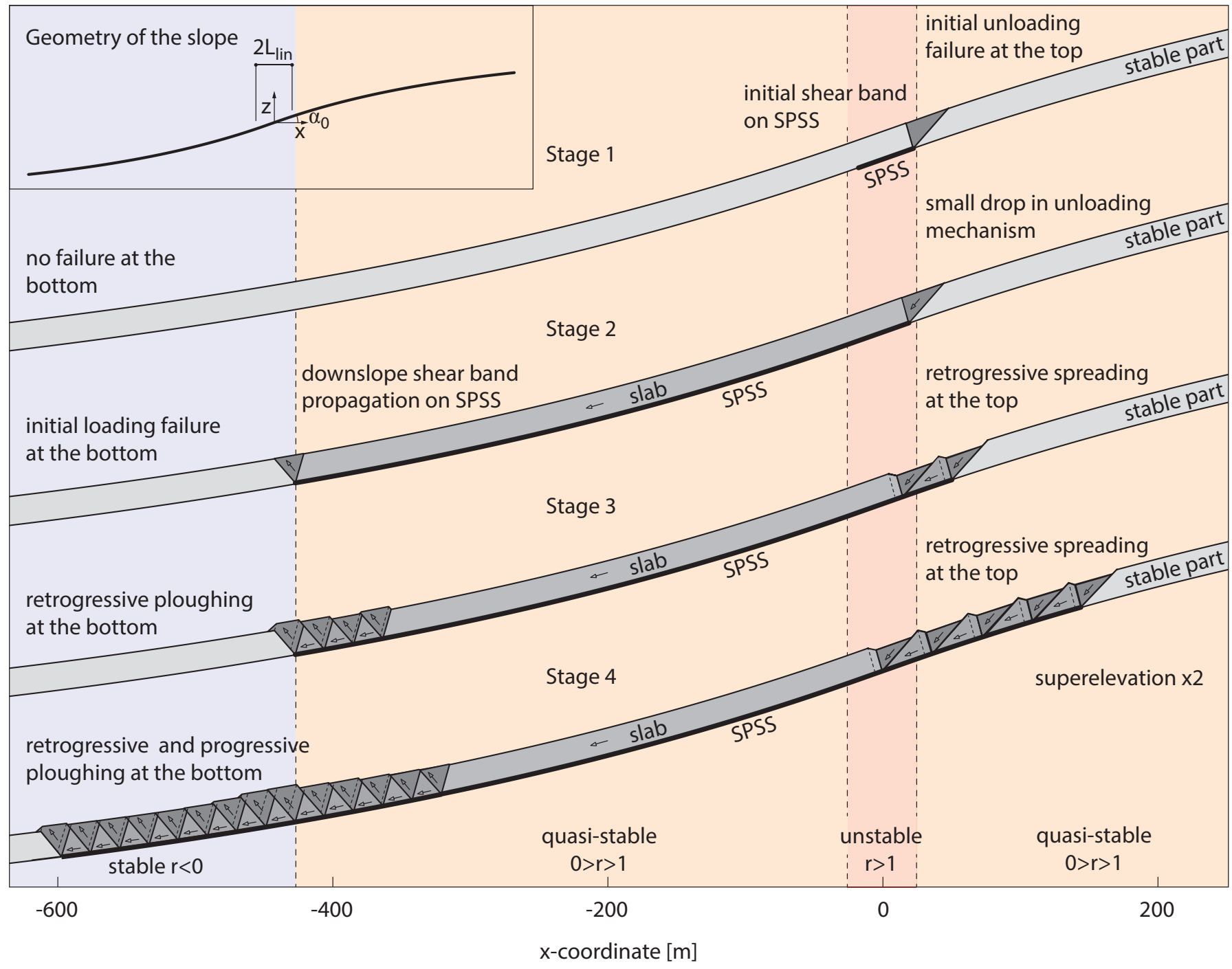

curve corresponds to the case of $L_{\mathrm{SBl}}=0$, i.e., the peak strength, $\tau_{\mathrm{p}}$, is mobilized along the entire base $L_{3}$ of block 3 in Fig. 11. The left curve presents the fully softened case of $L_{\mathrm{SB} 1}=L_{3}$, with only residual strength, $\tau_{\mathrm{r}}$, mobilized along $L_{3}$. The intersection of the thin solid black line (the loading force $Q_{p}$ ) with the left curve (point A) represents the value of the minimal critical heave, $u_{\mathrm{h}}^{\mathrm{cr}}$, for the case of the shear band propagating far into the stable part of the slope. The intersection of the thin solid black line with the right curve (point B) represents the value of the minimal critical heave, $u_{\mathrm{h}}^{\mathrm{cr}}$, that will cause ploughing even when no SBP takes place. In between these two extreme cases, the shear band propagates over a portion of the base of block $3 L_{\mathrm{SBl}}<L_{3}$ and the critical heave, $u_{\mathrm{h}}^{\mathrm{cr}}$, is found from the ploughing criterion in eq. (62) as a function of the SBP parameters $E \bar{\delta} /\left(\gamma^{\prime} h^{2}\right)$. In Fig. 12a these solutions are presented as horizontal lines for three different values of $E \bar{\delta} /\left(\gamma^{\prime} h^{2}\right)$, with the corresponding critical values of the loading force $Q_{p}$ causing ploughing given by the intersection of these horizontal lines with the solid black line. Based on the above considerations, the evolution of the critical load $Q_{\mathrm{p}}^{\mathrm{cr}}$ required for ploughing failure to take place is depicted by the thick solid black line: below point $\mathrm{A}$ it follows the left curve, above point $\mathrm{B}$ - the right curve; between $\mathrm{A}$ and $B$ it follows the $Q_{p}$ loading curve.

While in a curved slope it is likely that the initial failure of the sliding body occurs at $r=0$, further ploughing may progress into portions of the slope with lower or higher inclination. The corresponding required critical heave for ploughing is shown in Fig. 12b as a function of the shear stress ratio, $r$. For each value of $r$, the lower solid black curve presents the fully softened case $\left(L_{S B 1}=L_{3}\right)$, corresponding to point A in Fig. $12 a$, while the top solid black curve corresponds to the critical heave, $u_{\mathrm{h}}^{\mathrm{cr}}$, for the case of the peak strength $\left(L_{\mathrm{SB1}}=0\right)$, corresponding to point $\mathrm{B}$. Intermediate cases of SBP with $L_{\mathrm{SBl}}<L_{3}$ are given by dashed and dotted lines corresponding to three different values of $E \bar{\delta} /\left(\gamma^{\prime} h^{2}\right)$. Note that for $r>0$ and the fully softened SPSS (the lower solid black curve), ploughing does not require any heave in the seabed surface. In the stable zone, for $r<0$ and fully mobilized peak strength on the SPSS (the top solid black curve), starting from point $C$, even a heave equal to the full thickness of the sliding body is not sufficient to invoke ploughing failure of the next block. This leads to a run-out of the material from the sliding slab over the stable slope below.

\section{Example of a post-failure evolution in a curved slope}

\section{Model parameters}

The evolution of a submarine landslide using a numerical incremental integration of the developed KEB approach is illustrated by the following example. Consider the skew-symmetric S-shaped 
Table 2. Geometric parameters for example of submarine landslide evolution.

\begin{tabular}{ll}
\hline Parameter & Value \\
\hline$L_{\text {lin }}(\mathrm{m})$ & 20 \\
$H(\mathrm{~m})$ & 100 \\
$\alpha_{0}\left(^{\circ}\right)$ & 10 \\
\hline
\end{tabular}

slope in Fig. 13 with geometry built from a linear part (inclination $\alpha_{0}$ and length $2 L_{\text {lin }}$ ) in the middle with a smooth transition of height $H$ to horizontal slopes up- and downhill, described by the following exponential functions:

(63)

$$
\begin{cases}-L_{\text {lin }} \tan \alpha_{0}-H\left\{1-\exp \left[\frac{\left(x+L_{\text {lin }}\right)}{H} \tan \alpha_{0}\right]\right\} & \begin{array}{l}
\text { for } x<-L_{\text {lin }} \\
x \tan \alpha_{0} \\
\text { for }-L_{\text {lin }} \leq x \leq L_{\text {lin }}
\end{array} \\
L_{\text {lin }} \tan \alpha_{0}+H\left\{1-\exp \left[-\frac{\left(x+L_{\text {lin }}\right)}{H} \tan \alpha_{0}\right]\right\} & \text { for } x>L_{\text {lin }}\end{cases}
$$

The geometric parameters are given in Table 2. The shear strengths on the SPSS and in the sliding body have been adopted from Table 1. The SBP parameter is chosen as $E \bar{\delta} /\left(\gamma^{\prime} h^{2}\right)=2.4$, which results in larger critical heave and critical drop values and, hence, in a better visualization of the failure mechanisms in Fig. 13.

\section{Incremental integration of dynamic landslide evolution}

As the first step, an initial shear band on the SPSS in the unstable region is introduced, where the material has fully softened: stage 1 in Fig. 13. This leads to elastic unloading at the top and loading at the bottom end of the shear band. The force in the sliding body is compared with the criteria for initial unloading and loading failure in eqs. (18) and (41), respectively. In the presented example the unloading failure criterion (eq. (18)) is fulfilled immediately at the top end of the shear band and the first active block is formed, so that the further unloading involves both elastic and plastic deformations. In contrast, downslope deformations are elastic, driving downhill propagation of the shear band to the point where the force in the sliding body satisfies the criterion (eq. (41)) for initial loading failure, invoking the formation of a first passive block at the bottom of the slope: stage 2 in Fig. 13. However, even before this passive failure at the bottom takes place, the elastic deformation of the slab leads to further unloading and a small drop in height in the active failure mechanism at the top, related by eq. (23). Now that the global failure up- and downhill has taken place, the continuing downslope movement of the slab causes an additional drop of the seabed surface in the active mechanism and a heave in the passive mechanism, leading, respectively, to further unloading and loading described by eqs. (23) and (50). After each displacement increment the conditions (eq. (32)) for spreading at the top and (eq. (60)) for ploughing at the bottom are checked, and if fulfilled, the next failure mechanism is formed. In the presented example, first, in parallel with the uphill retrogressive spreading, the uphill (retrogressive) ploughing occurs: stage 3 in Fig. 13. (Note that the criterion for retrogressive ploughing is slightly different to that in eq. (60).) Later, downhill ploughing also takes place and, due to the significant downhill slab displacements, the retrogressive spreading blocks in the upper part of the slope are starting to move downslope: stage 4 in Fig. 13. The total kinetic energy of the system is calculated by summing up incrementally the kinetic energy of the moving slab together with the kinetic energy of all the spreading and ploughing mechanisms, calculated using eqs. (13) and (43), respectively. All kinetic energy components are calculated from the difference between the change in potential energy and plastic dissipation for the current displacement increment and the velocities taken from the previous step. The new value of the kinetic energy allows for the velocities to be updated (velocities of different blocks are related kinematically to the velocity of the slab). When the total kinetic energy reduces to zero, the landslide movement arrests and the final landslide geometry can be determined. Note that the stage 4 in Fig. 13, while already exhibiting the characteristic sliding block geomorphology observed in many submarine landslides (e.g., Kvalstad et al 2005; Gray et al 2015; Alves 2015), does not yet correspond to the final geometry.

\section{Summary and conclusions}

The paper applies the kinematic energy balance (KEB) approach based on the kinematic method of plasticity theory to the large deformation problem of initiation and propagation of the spreading and ploughing failure, at the top and bottom edges of a failed submarine slope, respectively. The models account for the phenomenon of a progressive propagation of a slope parallel slip surface, which is also quantified using the energy balance approach. The investigation of the evolution of the forces and postfailure geometry in the sliding layer allows for formulating spreading and ploughing criteria both in terms of the critical lateral forces and the critical drop (for spreading) and heave (for ploughing) of the seabed surface. These criteria appear to be strongly dependent not only on the shear strength on the slip surface and in the sliding body, but also on the stiffness of the sliding body and the strain-softening in the process zone of the propagating slip surface.

In contrast to existing approximate ad hoc analytical and numerical solutions, the proposed approach provides a rigorous theoretical basis for spreading and ploughing criteria. Furthermore, it has been demonstrated that the incremental energy balance equations, which were derived to define the above criteria, can also be used for deriving a comprehensive dynamic solution of the post-failure landslide evolution. Incremental integration of the kinetic energy in time allows for monitoring the development of normal forces in the sliding slab leading to the initiation of new kinematic failure mechanisms. Once a new mechanism forms, its deformation can be modelled using the same energy balance equations, resulting in the final post-failure geomorphology of the failed slope. Note, however, that because the mechanisms used in the large-displacement kinematic analysis, although admissible, are not necessarily true, the displacements calculated from such kinematics may become progressively inaccurate, even if the boundaries are updated continuously during the process. Therefore, the proposed mechanisms, while providing a more rigorous plasticity approach to the problem, require further validation against field observations.

Although the overflow of the sheared material over the stable slope below the failed slab has been incorporated into the ploughing mechanism, the limited scope of this paper did not allow for presenting derivations for the corresponding run-out criteria. These criteria will be presented in a subsequent publication that will complete the formulation of the KEB framework for the postfailure landslide evolution and enable its application to case studies.

\section{Acknowledgement}

The authors are grateful to the Swiss National Science Foundation (SNSF) for supporting this research with grant No. 200021_168998 "Dynamic evolution of submarine landslides".

\section{References}

Alonso, E.E., and Pinyol, N.M. 2010. Criteria for rapid sliding I. A review of Vaiont case. Engineering Geology, 114(3): 198-210. doi:10.1016/j.enggeo.2010.04.018.

Alves, T.M. 2015. Submarine slide blocks and associated soft-sediment deformation in deep-water basins: A review. Marine and Petroleum Geology, 67: 262-285. doi:10.1016/j.marpetgeo.2015.05.010.

Bryn, P., Berg, K., Forsberg, C., Solheim, A., and Kvalstad, T. 2005. Explaining the 
Storegga Slide. Marine and Petroleum Geology, 22(1-2): 11-19. doi:10.1016/j. marpetgeo.2004.12.003.

Chen, W.F. 1975. Limit analysis and soil plasticity. Amsterdam, the Netherlands: Elsevier Scientific Publishing Co.

Dey, R., Hawlader, B., Phillips, R., and Soga, K. 2015. Large deformation finite element modeling of progressive failure leading to spread in sensitive clay slopes. Géotechnique, 65(8): 657-668. doi:10.1680/geot.14.P.193.

Dey, R., Hawlader, B., Phillips, R., and Soga, K. 2016. Numerical modeling of combined effects of upward and downward propagation of shear bands on stability of slopes with sensitive clay. International Journal of Numerical and Analytical Methods in Geomechanics, 40(15): 2076-2099. doi:10.1002/nag. 2522.

Drucker, D.C., and Prager, W. 1952. Soil mechanics and plastic analysis or limit design. Quarterly of Applied Mathematics, 10(2): 157-165. doi:10.1090/qam/ 48291.

Einav, I., and Randolph, M.F. 2005, Combining upper bound and strain path methods for evaluating penetration resistance. International Journal for $\mathrm{Nu}-$ merical Methods in Engineering, 63: 1991-2016. doi:10.1002/nme.1350.

Gee, M.J.R., Gawthorpe, R.L., and Friedmann, J.S. 2005. Giant striations at the base of a submarine landslide. Marine Geology, 214(1-3): 287-294. doi:10.1016/ j.margeo.2004.09.003.

Germanovich, L., Kim, S., and Puzrin, A.M. 2016. Dynamic growth of slip surfaces in catastrophic landslides. Proceedings of the Royal Society of London. Series A, 472(2185): 20150758. doi:10.1098/rspa.2015.0758.

Gray, T.E., Puzrin, A.M., and Hill, A.J. 2015. Application of the shear band propagation method to slope stability analysis of a palaeo-landslide in the Caspian Sea. Proceedings of the Annual Offshore Technology Conference, Houston, Paper OTC-25869-MS.

Grilli, S.T., Shelby, M., Kimmoun, O., Dupont, N.G., Ma, D.G., Kirby, J.T., and Shi, F. 2017. Numerical simulation of subaerial and submarine landslide generated tsunami waves - recent advances and future challenges. National Hazards, 86(1): 353-391. doi:10.1007/s11069-016-2692-3.

Hampton, M.A., Lee, H.J., and Locat, J. 1996 Submarine landslides. Review of Geophysics, 34(1): 33-59. doi:10.1029/95RG03287.

Kvalstad, T.J., Andresen, L., Forsberg, C.F., Berg, K., Bryn, P., and Wangen, M. 2005. The Storegga slide: evaluation of triggering sources and slide mechanics. Marine and Petroleum Geology, 22: 245-256. doi:10.1016/j.marpetgeo. 2004.10.019

L'Heureux, J.S., Longva, O., Steiner, A., Hansen, L., Vardy, M.E., Vanneste, M., et al. 2012. Identification of weak layers and their role for stability of slopes at Finneidfjord, Northern Norway. In Proceedings of Submarine Mass Movements and their Consequences - 6th International Symposium. Advances in Natural and Technological Hazards Research book series. Springer, Dordrecht, pp. 321-330.

Locat, A., Leroueil, S., Bernander, S., Demers, D., Jostad, H.P., and Ouehb, L. 2011. Progressive failure in eastern Canadian and Scandinavian sensitive clays. Canadian Geotechnical Journal, 48(11): 1696-1712. doi:10.1139/t11-059.

Locat, A., Jostad, H.P., and Leroueil, S. 2013. Numerical modelling of progressive and its implications for spreads in sensitive clays. Canadian Geotechnical Journal, 50(9): 961-978. doi:10.1139/cgj-2012-0390.

Locat, J., and Lee, H.J. 2002 Submarine landslides: advances and challenges. Canadian Geotechnical Journal, 39(1): 193-212. doi:10.1139/t01-089.

Lovholt, F., Pedersen, G., and Harbitz, C.B. 2016. Tsunami-genesis due to retrogressive landslides on an inclined seabed. In Submarine mass movements and their consequences. Springer. pp. 569-578. doi:10.1007/978-3-319-209791 57.

Lovholt, F., Bondevik, S., Laberg, J.S., Kim, J., and Boylan, N. 2017. Some giant submarine landslides do not produce large tsunamis. Geophysical Research Letters. 44(16): 8463-8472. doi:10.1002/2017GL074062.

Masson, D.G., Harbitz, C.B., Wynn, R.B., Pedersen, G., and Lovholt, F. 2006. Submarine landslides: processes, triggers and hazard prediction. Philosophical Transactions of the Royal Society A, 364: 2009-2039. doi:10.1098/rsta. 2006.1810
Palmer, A.C., and Rice, J.R. 1973 The growth of slip surfaces in the progressive failure of over-consolidated clay. Proceedings of the Royal Society of London Series A, 332(1591): 527-548. doi:10.1098/rspa.1973.0040.

Peel, F.J. 2014. The engines of gravity-driven movement on passive margins: Quantifying the relative contribution of spreading vs. gravity sliding mechanisms. Tectonophysics, 633: 126-142.

Puzrin, A.M. 2016. Simple criteria for ploughing and runout in post-failure evolution of submarine landslides. Canadian Geotechnical Journal, 53(8): 13051314. doi:10.1139/cgj-2015-0582.

Puzrin, A.M., and Germanovich, L.N. 2005. The growth of shear bands in the catastrophic failure of soils. Proceedings of the Royal Society of London, A, 461(2056): 1199-1228. doi:10.1098/rspa.2004.1378.

Puzrin, A.M., Germanovich, L.N., and Kim, S. 2004. Catastrophic failure of submerged slopes in normally consolidated sediments. Géotechnique, 54(10): 631-643. doi:10.1680/geot.2004.54.10.631.

Puzrin, A.M., Saurer, E., and Germanovich, L.N. 2010. A dynamic solution of the shear band propagation in submerged landslides. Granular Matter, 12(3): 253-265. doi:10.1007/s10035-010-0177-8.

Puzrin, A.M., Gray, T.E., and Hill, A.J. 2015. Significance of the actual nonlinear slope geometry for catastrophic failure in submarine landslides. Proceedings of the Royal Society of London, A, 471(2175): 20140772. doi:10.1098/rspa.2014. 0772 .

Puzrin, A.M., Germanovich, L.N., and Friedli, B. 2016. Shear band propagation analysis of submarine slope stability. Géotechnique, 66(3): 188-201. doi:10. 1680/jgeot.15.LM.002.

Puzrin, A.M., Gray, T., and Hill, A.J. 2017. Retrogressive shear band propagation and spreading failure criteria for submarine landslides. Géotechnique, 67(2): 95-105. doi:10.1680/jgeot.15.P.078.

Quinn, P.E., Diederichs, M.S., Rowe, R.K., and Hutchinson, D.J. 2011. A new model for large landslides in sensitive clay using a fracture mechanics approach. Canadian Geotechnical Journal, 48(8): 1151-1162. doi:10.1139/t11-025.

Quinn, P.E., Diederichs, M.S., Rowe, R.K., and Hutchinson, D.J. 2012. Development of progressive failure in sensitive clay slopes. Canadian Geotechnical Journal, 49(7): 782-795. doi:10.1139/t2012-034.

Sultan, N., Savoye, B., Jouet, G., Leynaud, D., Cochonat, P., Henry, P.,, et al. 2010. Investigation of a possible submarine landslide at the Var delta front (Nice continental slope southeast France). Canadian Geotechnical Journal, 47(4): 486-496. doi:10.1139/T09-105.

Trapper, P.A., Puzrin, A.M., and Germanovich, L.N. 2015. Effects of shear band propagation on early waves generated by initial breakoff of tsunamigenic landslides. Marine Geology, 370: 99-112. doi:10.1016/j.margeo.2015.10.014.

Vanneste, M., Forsberg, C.F., Sylfest, G., Harbitz, C.B., Issler, D., Kvalstad, T.J., et al. 2013. Submarine landslides and their consequences: What do we know, what can we do? In Landslide science and practice. Springer-Verlag, Berlin, Heidelberg, pp. 5-17.

Viesca, R.C. and Rice, J.R. 2012. Nucleation of slip-weakening rupture instability in landslides by localized increase of pore pressure. Journal of Geophysical Research, 117(B03104). doi:10.1029/2011JB008866.

Zhang, W., Wang, D., Randolph, M.F., and Puzrin, A.M. 2015. Catastrophic failure in planar landslides with a fully softened weak zone. Géotechnique, 65(9): 755-769. doi:10.1680/geot14.P.218.

Zhang, W., Wang, D., Randolph, M.F., and Puzrin, A.M. 2016. Dynamic propagation criteria for catastrophic failure in planar landslides. International Journal for Numerical and Analytical Methods in Geomechanics, 40(17): 2312-2338. doi:10.1002/nag.2531.

Zhang, W., Wang, D., Randolph, M.F., and Puzrin, A.M. 2017. From progressive to catastrophic failure in submarine landslides with curvilinear slope geometries. Geotechnique. doi:10.1680/jgeot.16.P.249.

Zhang, W., Wang, D., Randolph, M.F., and Puzrin, A.M. 2019. Transition from shear band propagation to global slab failure in submarine landslides. Canadian Geotechnical Journal. [In press.] doi:10.1139/cgj-2017-0648. 